\title{
Creating positive, negative, and neutral primes and testing their impact on scrupulosity relevant tasks and symptoms
}

\author{
Kelsey Jean Evey \\ West Virginia University, kje0007@mix.wvu.edu
}

Follow this and additional works at: https://researchrepository.wvu.edu/etd

Part of the Clinical Psychology Commons

\section{Recommended Citation}

Evey, Kelsey Jean, "Creating positive, negative, and neutral primes and testing their impact on scrupulosity relevant tasks and symptoms" (2020). Graduate Theses, Dissertations, and Problem Reports. 7579.

https://researchrepository.wvu.edu/etd/7579

This Thesis is protected by copyright and/or related rights. It has been brought to you by the The Research Repository @ WVU with permission from the rights-holder(s). You are free to use this Thesis in any way that is permitted by the copyright and related rights legislation that applies to your use. For other uses you must obtain permission from the rights-holder(s) directly, unless additional rights are indicated by a Creative Commons license in the record and/ or on the work itself. This Thesis has been accepted for inclusion in WVU Graduate Theses, Dissertations, and Problem Reports collection by an authorized administrator of The Research Repository @ WVU. For more information, please contact researchrepository@mail.wvu.edu. 
Creating positive, negative, and neutral primes and testing their impact on scrupulosity relevant tasks and symptoms

Kelsey J. Evey, B.S.

Thesis submitted

to the Eberly College of Arts and Sciences

at West Virginia University

in partial fulfillment of the requirements for the degree of

Master of Science in

Psychology

Shari Steinman, Ph.D., Chair

Natalie Shook, Ph.D.

Julie Hicks Patrick Ph.D.

Department of Psychology

Morgantown, West Virginia

2020

Keywords: scrupulosity, obsessive-compulsive disorder, religion

Copyright 2020 Kelsey Evey 


\section{Abstract \\ Creating positive, negative, and neutral primes and their impact on scrupulosity relevant}

\section{tasks and symptoms}

\section{Kelsey J. Evey}

A series of three studies was conducted to develop and validate primes to activate negative, positive, or neutral beliefs about God and to determine how these activated beliefs impact scrupulosity signs and symptoms. Scrupulosity is a specific presentation of obsessivecompulsive disorder (OCD) in which individuals become preoccupied and distressed by intrusive thoughts and images related to religious issues. Individuals with more severe scrupulosity often have more negative beliefs about God. Christianity conceptualizes God in both positive (e.g., loving, caring, and helpful) and negative (e.g., angry, judgmental, and wrathful) terms. It is therefore important to determine how more positive, negative, or neutral beliefs about God influence scrupulosity symptoms in order to improve treatment efficacy for scrupulosity. In Study 1, potential primes were created from Bible verses and rated on arousal, valence, familiarity, and complexity by participants self-identifying as Christian. In Study 2, the selected positive, negative, and neutral primes were tested to determine if they differentially activated positive and negative beliefs about God. Results indicated that participants in the negative prime condition had more negative and less positive beliefs about God than participants in the positive and neutral prime condition. In Study 3, Christian participants read one of the three primes described above. Next, participants completed a thought-induction task and measures of thoughtaction fusion and scrupulosity. There were no significant differences in reactions to the thoughtinduction task or self-report measures of scrupulosity or thought-action fusion between conditions. However, participants in the negative condition had significantly higher state anxiety following the prime, compared to participants in the positive condition. Results demonstrate the ability of the negative prime to activate negative beliefs about God and highlight the detrimental impact negative beliefs about God may have on state anxiety. 


\section{Table of Contents}

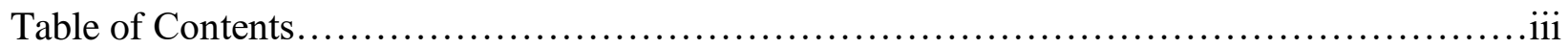

Introduction. ......................................................................

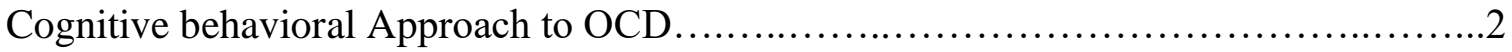

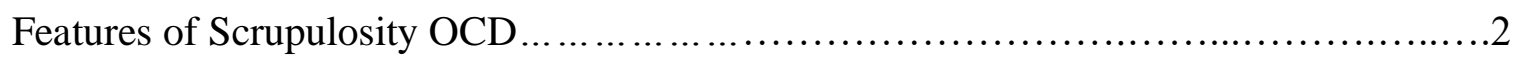

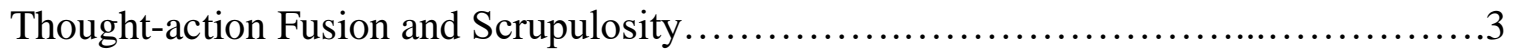

Conceptualization of God and Religious Primes................................4

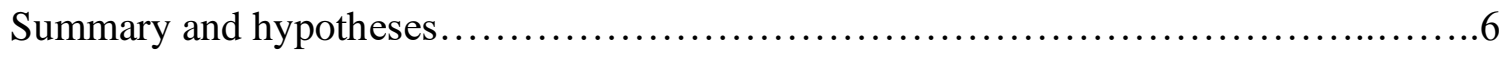

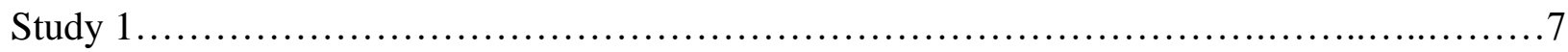

Study 1 Methods........................................................

Study 1 Measures...................................................

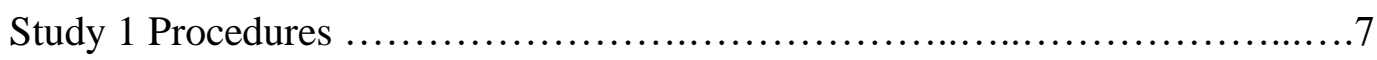

Study 1 Results............................................................... 8

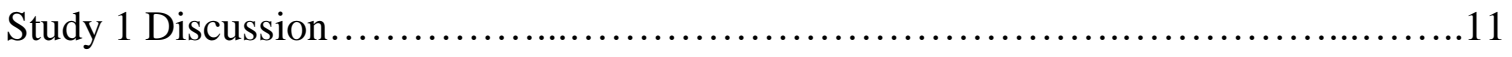

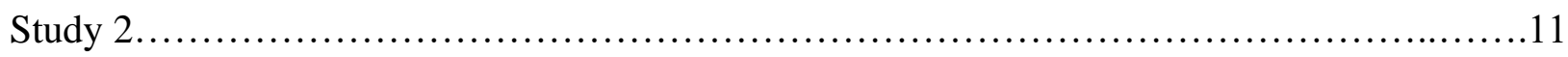

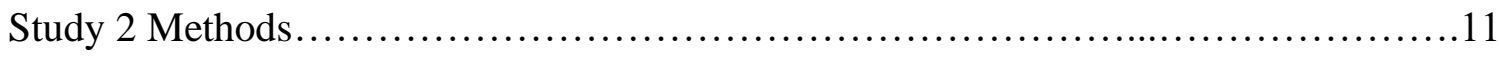

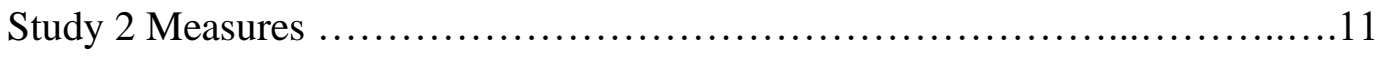

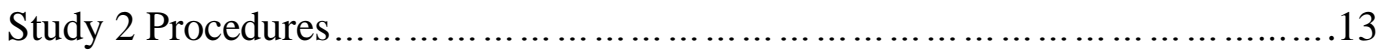

Study 2 Results........................................................ 13

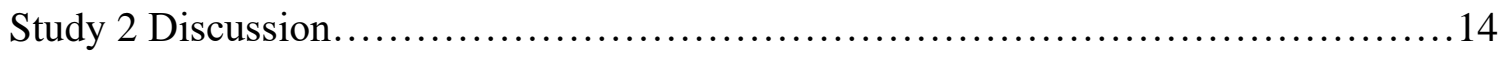

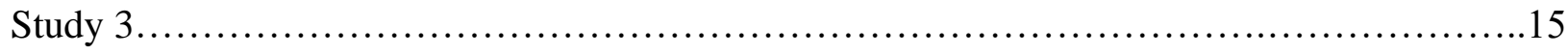

Study 3 Methods ................................................................ 16

Study 3 Measures...................................................16 


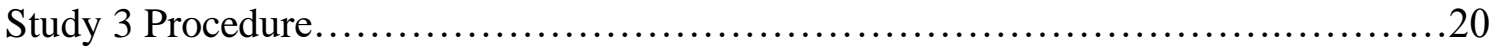

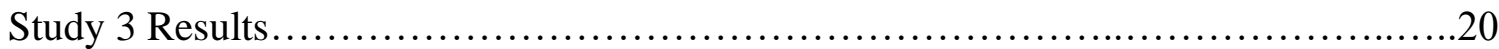

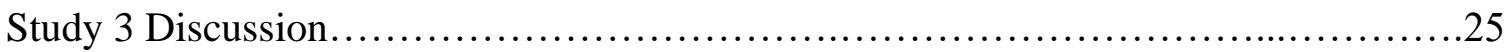

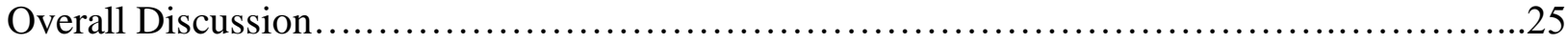

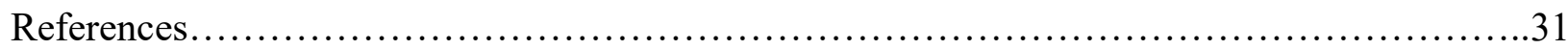

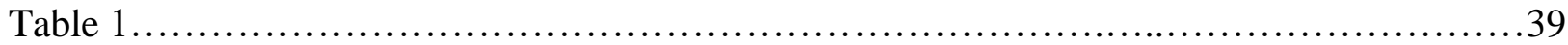

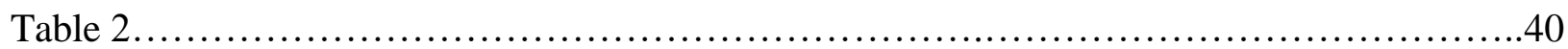

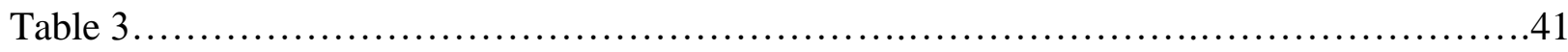

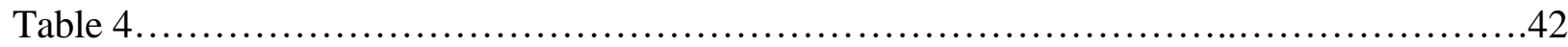

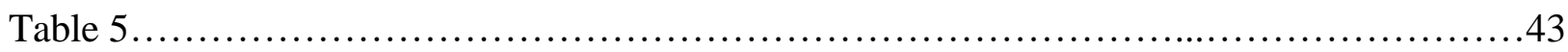

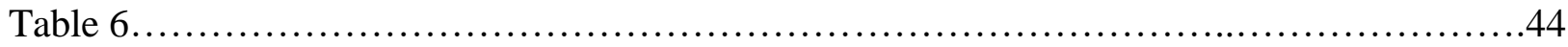

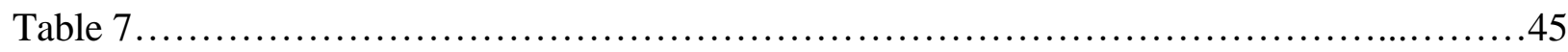

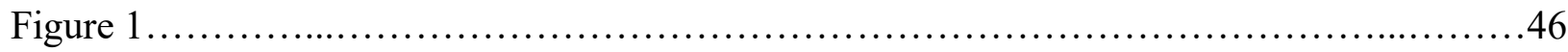

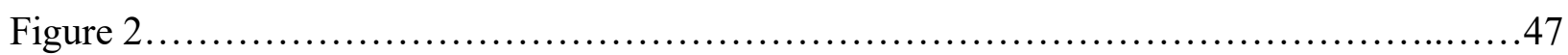

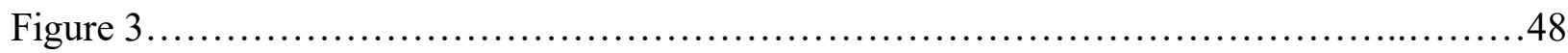

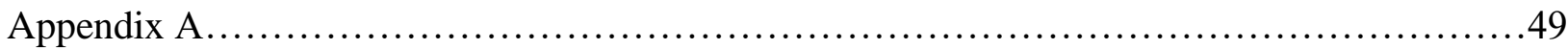

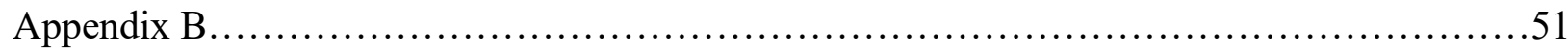

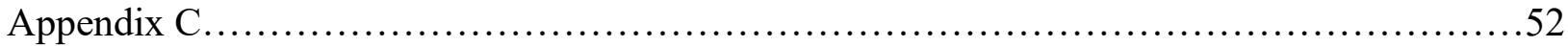

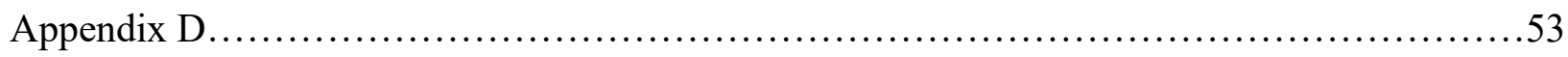

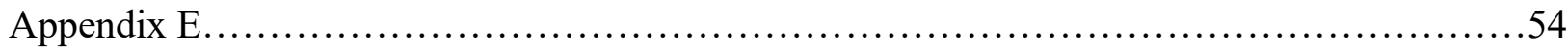

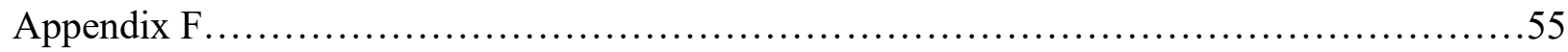

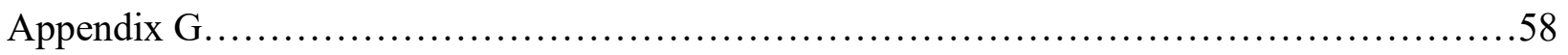


Creating positive, negative, and neutral primes and their impact on scrupulosity relevant tasks and symptoms

Scrupulosity is a prevalent and detrimental manifestation of obsessive-compulsive disorder (OCD; Abramowitz et al., 2002; Abramowitz \& Jacoby, 2014; Foa \& Kozak, 1995; Miller \& Hedges, 2008;). OCD is defined by the experience of intrusive (i.e. unwanted and distressing) thoughts followed by compulsive behaviors to alleviate the anxiety experienced from these intrusive thoughts (Abramowitz et al., 2005). Individuals with scrupulosity are preoccupied and distressed by intrusive thoughts and images related to religious or moral issues (Abramowtiz et al., 2002; Abramowitz \& Jacoby, 2014; Pirutinsky et al., 2015). Common obsessional themes for scrupulosity include fear of committing a sin, intrusive images or thoughts considered sacrilegious or blasphemous, and fear of punishment by God or going to Hell (Abramowitz et al., 2002). Consequently, individuals with scrupulosity perform compulsive behaviors to alleviate anxiety and/or guilt from the intrusive thoughts described above (American Psychiatric Association, 2013; Abramowitz et al., 2002; Miller \& Hedges, 2000). Common compulsions for scrupulosity include excessive praying (i.e., praying repeatedly following an intrusive thought to the point it may interfere with daily functioning), attention to small and minor details of one's religion, and seeking reassurance from prominent religious figures or family members (Abramowitz et al., 2002)

Several studies have confirmed the high prevalence of religious obsessions and compulsions in adults and adolescents with OCD (Akhtar et al., 1978; Eisen et al., 1997; MataixCols et al., 2002; Shooka et al., 1998). One study indicated that $24.2 \%$ of a Toronto clinic sample of adults and adolescents with OCD reported religious obsessions (Summerfeldt et al., 1997), and in more religious societies, the rate of 
religious obsessions is even higher - up to $50 \%$ of patients in Saudi Arabia and $60 \%$ of patients in Egypt report religious obsessions (Mahgoub, \& Abdel-Hafeiz, 1991; Okasha et al., 1994). Furthermore, individuals can have symptoms of scrupulosity without meeting full diagnostic criteria for OCD, as OCD (and scrupulosity) exists on a continuum of severity (Gibbs, 1996).

\section{Cognitive behavioral approach to scrupulosity}

According to cognitive models of OCD (including scrupulosity), experiencing intrusive thoughts is common (Rachman, 1997; Rachman \& DeSilva, 1978). Most people recognize intrusive thoughts as "noise" and don't attach meaning to these thoughts. However, some people - those more likely to develop OCD — misinterpret these thoughts as significant and believe the thoughts have catastrophic consequences (e.g., the thoughts will cause someone to get into a car accident or prevent them from going to Heaven), which produces internal distress (i.e., fear and/or guilt) (Rachman, 1997, 1998). They then engage in compulsive actions, such as praying or asking for reassurance, to alleviate this distress (Abramowitz \& Jacoby, 2014).

\section{Features of Scrupulosity OCD}

For individuals with scrupulosity, symptoms of their disorder interfere with their daily functioning, especially their religious experience (Siev et al., 2011). For example, it is common for individuals with scrupulosity to avoid religious services and religious symbols that could trigger obsessions (Abramowitz \& Jacoby, 2014). Scrupulosity symptoms also extend past what is required by religious law and focus on peripheral religious issues at the expense of central religious tenets, negatively affecting one's religious experience (Abramowitz \& Jacoby, 2014). Although individuals with scrupulosity engage in behaviors endorsed by their religion, they engage in these behaviors to reduce distress and anxiety rather than to strengthen their relationship with God. For example, individuals with scrupulosity often focus on praying in a 
specific manner rather than focusing on connecting with God through prayer or spend time confessing minor sins out of fear instead of pursuing a sinless life as a way to be close to God. Thus, while individuals with healthy religious practices may experience positive outcomes in relation to their religious actions, those with scrupulosity experience negative emotions during their religious obsessions and compulsive behaviors.

Individuals with scrupulosity have poorer insight into their obsessions and compulsions than individuals with other presentations of OCD (e.g., harm obsessions or contamination fears; Tolin et al., 2001), meaning they are less likely to view their obsessions and compulsions as irrational and unrealistic. Scrupulosity is also associated with increased magical ideation (belief in causal patterns incompatible with conventional standards) compared to other forms of OCD (such as obsessions about contamination or dying; Tolin et al., 2001). Furthermore, individuals with scrupulosity are often intolerant of uncertainty and require absolute proof that their beliefs are correct (Abramowitz \& Jacoby, 2014). However, many of the religious obsessions in scrupulosity make absolute proof difficult or impossible (i.e., "Did I do enough confessing?" or “Have I behaved morally enough?"), which causes distress and anxiety. Individuals with scrupulosity are more likely to seek pastoral counseling (i.e., going to a pastor for advice on how to manage their symptoms) and less likely to choose medical treatment for their symptoms (Siev et al., 2011), further decreasing the likelihood they will experience relief from their symptoms. Additionally, research suggests poor treatment outcomes for therapy-seeking scrupulosity patients (Alonso et al., 2001; Ferrao et al., 2006; Mataix-Cols et al., 2002; Rufer et al., 2005). Thus, although research suggests that scrupulosity does not indicate a more severe form of OCD, it may be an especially distressing form of the disorder (Nelson et al., 2006).

\section{Thought-Action Fusion and Scrupulosity}


Individuals with scrupulosity OCD are particularly prone to moral thought-action fusion (moral TAF), a cognitive distortion equating thoughts and behavior. Simply put, moral TAF is the belief that thoughts and actions are morally equivalent (e.g., having a blasphemous thought is as sinful as a blasphemous action) (Shafran et al., 1996). Moral TAF contributes to the misinterpretation of thoughts as dangerous and needing to be controlled (Muris et al., 2001; Rassin et al., 2000). Thus, moral TAF may contribute to the development and maintenance of OCD by increasing fear and anxiety associated with intrusive thoughts.

Within Christianity, religious doctrine may contribute to the development of moral TAF. Doctrine creates strict moral standards for thinking and behaving, and these standards are often reinforced by religious figures and/or the threat of punishment (Abramowitz et al., 2014). Bible passages such as Mark 7:21 ("For from within, out of the heart of man, come evil thoughts, sexual immorality, theft, adultery") and Matthew 5:28 ("But I say to you that anyone who looks at a woman with lustful intent has already committed adultery with her in his heart") perpetuate the idea that thoughts and actions are morally equivalent and that thoughts must be controlled to escape sin and punishment. Notably, moral TAF is higher in Christianity than other religions and those with no religious affiliation (Cohen \& Rozin, 2001; Siev \& Cohen, 2007; Siev et al., 2010; Berman et al., 2010; Rassin \& Koster, 2003). Moral TAF may influence how individuals with scrupulosity OCD view God as individuals may worry that their "unacceptable" thoughts will be punished or upset God.

\section{Conceptualization of God and Religious Primes}

Abramowitz (2002) proposed that individuals with scrupulosity conceptualize God as angry, vengeful, and punishing. Similarly, multiple studies demonstrated that the severity of scrupulosity is correlated with more negative beliefs about God (Pirutinsky et al., 2015; Siev et 
al., 2011). These results suggested that individuals with scrupulosity symptoms may not be attuning to the positive descriptors of God and may be overly focused on negative descriptors, which may be contributing to and maintaining scrupulosity symptoms. Conversely, positive beliefs about God have been associated with better mental health outcomes-including for obsessions (Flannelly et al., 2009; Silton et al., 2014). Current suggestions for treating individuals with scrupulosity therefore include discussing negative assumptions about God (Abramowitz \& Jacoby, 2014).

Some research has explored the relationship between religious primes, anxiety, and scrupulosity symptoms.1 For instance, a series of studies by Inzlicht and Tullett (2010) found that consciously priming religion by writing about what religion meant to the participants personally and unscrambling sentences containing religious words (i.e., spirit, sacred, divine) decreased anxious reactions to self-generated errors on a color-naming Stroop task. Thus, reflecting on religion seemed to reduce anxiety about making mistakes. Others have found that priming religion prior to a punishment game and an anagram task caused anxiety by possibly eliciting evaluative concerns about God watching and monitoring one's behavior (McKay et al., 2011; Toburen \& Meier, 2010). Finally, Fergus and Rowatt (2015) found that an uncertainty prime (i.e., asking participants to describe the emotions they experience when they are uncertain and their physical reactions to uncertainty) interacted with a religion prime (i.e., having participants unscramble sentences containing religious words like divine and sacred) to increase fear of $\sin -$ a construct related to scrupulosity. Notably, all of the above primes targeted religion broadly, rather than beliefs about God specifically. Having individuals unscramble sentences or write about religion does not ensure that beliefs about God are primed. Instead, individuals could be

1 Articles refer to the religion primes used as God concept primes. 
thinking about religious norms and rules, prominent religious figures (i.e., pastors and clergy), the social ramifications of religion, etc. To our knowledge, no validated primes exist that specifically modify participants' beliefs about God.

\section{Summary and Hypotheses}

In the current series of studies, we aimed to develop primes that can directly activate beliefs about God, clarify the role beliefs about God have in scrupulosity symptoms, and evaluate if the primes impact a scrupulosity-relevant task. We developed primes designed to activate positive, negative, and neutral beliefs about God (Study 1), examined the effectiveness of the primes created in Study 1 (Study 2), and tested if the primes affected self-reported scrupulosity symptoms and related behaviors (Study 3).

We did not have a priori hypotheses for Studies 1 and 2, given that they involved initial development (Study 1) and validation (Study 2) of the primes. In Study 3, participants were randomly assigned to read one of the three primes developed in Studies 1 and 2. We hypothesized that, following the prime, groups would differ in 1) the negativity/positivity of their beliefs about God, 2) their responses to the thought-induction task, and 3) self-reported levels of scrupulosity and thought-action fusion. Specifically, we expected individuals in the negative prime group to have the most negative and least positive beliefs about God, the most negative responses to the thought- induction task (i.e., higher levels of anxiety, stronger moral unacceptability, stronger desires to cancel out effects of task, etc.), and the highest self-reported levels of scrupulosity and thought-action fusion. We did not expect differences between individuals in the neutral and positive prime groups. 


\section{Study 1}

The purpose of Study 1 was to create groups of Bible verses that could potentially activate positive, negative, and neutral beliefs about God. Verses were rated on arousal, valence, familiarity, and complexity by self-identified Christians, as it was hypothesized that these were relevant constructs that could impact the effectiveness of our primes. Participants were compensated two dollars and fifty cents for participating in this 45 -minute study.

\section{Study 1 Methods}

\section{Study 1 Measures}

Demographics. Relevant demographic information such as gender, age, and ethnicity was collected. See Table 1.

Participants. Participants identifying as Christian, aged 18 or older, from the United States, and able to read English were recruited through MTurk (an Internet-based platform that aids researchers in crowdsourcing) to participate in this study. Data from 67 eligible participants was collected, $\mathrm{n}=19$ were excluded because they failed to complete the study (only participants that completed the study were retained to correct for an experimenter error [unclear if multiple noncompleters were actual participants or practice participants) Thus, 48 participants (83.3\% white, $77.1 \%$ male, mean age $=37.85, S D=13.42$, age range $=23-72$ ) were included in the following analyses. See Table 3.

\section{Study 1 Procedure}

To create the primes, the author and two undergraduate research assistants compiled a list of 61 verses from the Old and New Testament of the New Living Translation of the Bible that described God in positive, negative, or neutral terms. The New Living Translation was used because of its modern language and ease of reading compared to other versions of the Bible. 
Each verse was rated on valence (how positively or negatively the verse described God), arousal, complexity, and familiarity on 9-point Likert scales. Higher valence ratings indicated higher levels of positivity and lower valence ratings indicated higher levels of negativity. Arousal was measured using the 9-point Self-Assessment Manikin (SAM) developed for the International Affective Picture System (IAPS; Lang, 1980; Hodes et al., 1985). SAs an attention check, participants saw seven items throughout the questionnaire asking them to select certain answers as an attention check.

Verses were grouped into possible primes to elicit negative, positive, and neutral beliefs about God. To be considered a possible prime, verse groupings needed to meet the following criteria: (a) valence needed to be significantly different for the positive, negative, and neutral conditions with the positive verses having the highest valence rating followed by the neutral condition and then the negative condition, (b) arousal needed to be significantly different between the neutral and positive verse conditions and between the neutral and negative verse condition, as we conceptualized more emotionally valenced verses would be more arousing, (c) prime conditions could not differ significantly in familiarity and complexity, or if a significant difference did exist, results for arousal and valence needed to remain the same when familiarity and/or complexity was included as a covariate. In addition, primes needed to have an approximately equal word count across conditions. Several possible verse groupings satisfied these conditions (three verses per condition, five verses per condition, six verses, and eight verses per condition) and will be discussed below.

\section{Study 1 Results}

To determine if primes met the above criteria for valence (i.e., valence significantly differed for the positive, negative, and neutral conditions with the positive verses having the 
highest valence rating followed by the neutral condition and then the negative condition), a series of repeated-measures ANOVAs with three within-subjects variables (mean valence of the positive verses, mean valence of the negative verses, and mean valence of the neutral verses) for the three verse, five-verse, six-verse, and eight-verse primes. All of the ANOVAs were significant (three verses: $F_{(2,46)}=22.83, p<.001$, partial $\eta 2=.50$; five verses: $F_{(2,46)}=23.23, p<.001$, partial $\eta_{2}=.50$; six verses: $F_{(2,46)}=33.55, \mathrm{p}<.001$, partial $\eta_{2}=.59$; eight verses: $F(2,46)=35.77$, $p<.001$, partial $\left.\eta_{2}=.61\right)$. To interpret interactions, three follow-up paired-samples t-tests were conducted. Results indicated that mean valence differed in the expected direction for all followup tests $(p<.001)$.

To determine if primes met the above criteria for arousal, (i.e., arousal significantly differed between the neutral and positive verses and between the neutral and negative verses), we conducted a second series of repeated-measures ANOVAs with three within-subjects variables (mean arousal of the positive verses, mean arousal of the negative verses, and mean arousal of the neutral verses) for the three verse, five-verse, and six-verse primes. All ANOVAs were significant (three verses: $F(2,46)=5.45, p=.006$, partial $\eta_{2}=.19$; five verses: $F(2,46)=4.18, p=.020$, partial $\eta_{2}=.15$; six verses: $F_{(2,46)}=7.23, p=.002$, partial $\eta_{2}=.24$; eight verses: $F_{(2,46)}=5.16, p=.002$, respectively). To interpret interactions, three follow-up paired-samples t-tests with mean arousal as the dependent variable were conducted for each prime. For all of the primes, arousal differed in the expected direction $(p>.05$ between the positive and negative verses and $p<.05$ between the neutral and negative verses and between the neutral and positive verses; see Table 1.

To determine if primes met criteria for familiarity (i.e., prime conditions could not differ significantly in familiarity or results for arousal and valence remained the same when familiarity was included as a covariate), a third series of repeated-measures ANOVAs with three within- 
subjects variables (mean familiarity of the positive verses, mean familiarity of the negative verses, and mean familiarity of the neutral verses) for the prime groups were conducted. There was no significant difference in mean familiarity between the three-verse primes $\left(F_{(2,46)}=2.31\right.$, $p=.11$, partial $\left.\eta_{2}=.09\right)$ or the five-verse primes $\left(F_{(2,46)}=.23, p=.80\right.$, partial $\left.\eta_{2}=.01\right)$. However, there were significant differences in familiarity for the six-verse primes $\left(F_{(2,46}=6.89, p=.003\right.$, partial $\left.\eta_{2}=.23\right)$ and the eight verse primes $\left(F_{(2,46)}=12.57, p<.001\right.$, partial $\left.\eta_{2}=.35\right)$. Analyses were re-run for valence and arousal for the six- verse and eight-verse primes with familiarity as a covariate, and the pattern of results remained the same.

To determine if the primes met criteria for complexity (i.e., prime conditions could not differ significantly in complexity or results for arousal and valence remained the same when familiarity was included as a covariate) a fourth series of repeated-measures ANOVAs with three within-subjects variables (mean complexity of the positive verses, mean complexity of the negative verses, and mean complexity of the neutral verses) for the prime groups were conducted. There was no significant difference in mean familiarity between the three verse, five verse, or the six-verse primes (three verses: $F_{(2,46)}=1.18, p=.32$, partial $\eta_{2}=.05$; five verses: $F_{(2,46)}=.27, p=.76$, partial $\eta 2=.01$; six verses: $F_{(2,46)}=1.86, p=.17$, partial $\left.\eta_{2}=.08\right)$. However, there was a significant difference in complexity for the eight verse primes $\left(F_{(2,46)}=6.35, p=.004\right.$, partial $\eta 2=.22$ ). Analyses were re-run for valence and arousal for the eight- verse primes with complexity as a covariate, and the pattern of results remained the same. See Table 1 for information on means and standard deviations for valence, arousal, familiarity, and complexity of the prime groupings. 


\section{Study 1 Discussion}

After asking participants to rate the valence, arousal, familiarity, and complexity of 61 Bible verses, we were able to develop groupings of Bible verses that portrayed God in an explicitly positive, negative, or neutral manner. Four different lengths of primes met the criteria described above - three verses per condition, five verses per condition, six verses per condition, and eight verses per condition. To our knowledge, this is the first study in which primes designed to activate negative, positive, and neutral beliefs about God were systematically rated on relevant constructs by those self-identifying as Christian. However, due to the fairly small sample size used in this study, it is possible that the results of this study are not generalizable to all people identifying as Christian. In addition, it is also possible that individuals who do not actually consider themselves Christian completed the study as there was no validity check for religious affiliation.

\section{Study 2}

The purpose of Study 2 was to determine if the primes created in Study 1 could successfully activate positive, negative, and neutral beliefs about God. We considered a negative prime successful if individuals in the negative verse condition rated God more negatively than those in the positive and neutral verse conditions. We considered a positive prime successful if individuals in the positive verse condition rated God more positively than those in the negative and neutral verse conditions. Participants were compensated one dollar for participating in this 20-minute study.

\section{Study 2 Methods}

\section{Study 2 Measures}


Demographics. Relevant demographic information such as gender, age, and ethnicity was collected.

Participants. Participants identifying as Christian, aged 18 or older, from the United States, and able to read English were recruited through MTurk to participate in this study. Individuals who completed Study 1 were not eligible for this study. Data from 233 participants was collected. Data from three participants was excluded (one did not provide Mturk code, one did not complete at least $50 \%$ of questions, and one due to experimenter error [unclear if participant with an actual participant or a practice participant]). Analyses were run with and without these three excluded participants and the pattern of results did not change. Thus, 230 participants (64.3\% white; $57.4 \%$ male; Mean age $=34.40, S D=10.41$; age range=20-69) were included in the following analyses.

Concepts of God Checklist. On a scale of 1 ("strongly disagree") to 5 ("strongly agree"), participants rated how well they believed various adjectives described God (modified from Siev et al., 2011). This scale is comprised of two subscales: Positive Concepts of God and Negative Concepts of God (Siev et al., 2011). Six words are included on the positive subscale: peaceful, kind, comforting, gentle, compassionate, and loving. The six words comprising the negative subscale are punishing, fearsome, terrifying, jealous, angry, and vengeful. A composite average score is created for both subscales (Siev et al., 2011). The Concepts of God Checklist was administered to test if the positive, negative, and neutral verse groupings affected positive and negative beliefs about God (Positive Concepts of God Cronbach's $\alpha=.92$; Negative Concepts of God Cronbach's $\alpha=.90$ ) 


\section{Study 2 Procedure}

Participants were randomized to one of 12 primes developed in Study 1. Participants were instructed to slowly and carefully read the verses they were presented with for three minutes and to re-read them if they finished before time expired. Immediately after reading the verses, participants completed the Concepts of God Checklist.

\section{Study 2 Results}

A preliminary analysis of the data indicated no differences in age, gender, ethnicity, race, or religious affiliation between conditions. To determine if any of the primes activated positive, negative, or neutral beliefs about God, a repeated-measures ANOVA was conducted with prime condition (positive, negative, or neutral verses) as the between-subjects factor and Concepts of God subscale (positive, negative) as a within-subjects variable. The repeated-measures ANOVA indicated a significant interaction between prime condition (i.e., three positive, three negative, three neutral, five positive, five negative, five neutral, six positive, six negative, six neutral, eight positive, eight negative, and eight neutral verses) and the Concepts of God Checklist $\left(F_{(11,218)}=6.82, p<.001\right.$, partial $\left.\mathrm{y}_{2}=.26\right)$.

To interpret this interaction, separate one-way ANOVAs for the positive and negative Concepts of God subscales were conducted, with prime condition (three positive, three negative, three neutral, five positive, five negative, five neutral, six positive, six negative, six neutral, eight positive, eight negative, and eight neutral verses) as a between-subjects variable. The ANOVAs revealed significant differences in the Positive Concepts of God subscale and the Negative Concepts of God subscale between primes $\left(F_{(11,218)}=4.65, p<.001\right.$ partial $\eta_{2}=.19 ; F_{(11,218)}=4.75$, $p<.001$, partial $\mathrm{y}_{2}=.19$, respectively). For the positive subscale, follow-up Tukey post hoc tests revealed that positive beliefs about God differed across all of the six-verse groupings (positive > 
neutral > negative verses, all $p<.01)$ except there was not a significant difference between the positive and neutral six-verse prime $(p=1.00)$. For the negative subscale, Tukey post hoc analyses also indicated that negative beliefs about God differed across all of the six-verse primes (negative $>$ neutral $>$ positive verses, all $p<.05$ ) except there was not a significant difference between the positive and the neutral six-verse prime $(p=.76)$. No other primes (three verses, five verses, and eight verses per condition) demonstrated this pattern of results for the positive and negative subscale of the Concepts of God Checklist (see Table 2).

\section{Study 2 Discussion}

The six-verse negative prime activated negative beliefs about God. Individuals in the sixverse negative prime condition rated God significantly more negatively (i.e., angry, punishing, etc.) than those in the six-verse positive and neutral prime conditions. In addition, individuals in the six-verse negative prime condition rated God significantly less positively (i.e., loving, kind, etc.) than those in the six-verse positive and neutral primes. These results indicate that negative beliefs about God can be activated (at least briefly) with even a relatively short prime.

It is possible that the six-verse negative prime successfully activated negative beliefs about God while the three, five, and eight-verse primes did not because the six-verse prime increased the dosage of "negative God" information that participants received without being overburdening.

There was no significant difference in positive beliefs about God or negative beliefs about God between the neutral and positive condition. First, it is possible that the positive prime did not activate positive beliefs about God. It also may be that it is impossible to have neutral beliefs about God. Most Christians learn about the nature of God from friends, family, and clergy/pastors, and it is possible that this prior learning influences the interpretation of seemingly 
neutral Bible verses. Furthermore, it is also possible that there is not a meaningful or practical difference between positive and neutral beliefs about God, explaining why nonsignificant results between the neutral and positive condition were obtained in this study. Research indicates that negative beliefs about God are associated with increased scrupulosity symptoms, while data suggests that positive beliefs about God are not correlated with symptoms of scrupulosity (Pirutinsky et al., 2015; Siev et al., 2011). Thus, it may not be important to differentiate between neutral and positive beliefs about God as negative beliefs about God appear to be more influential for scrupulosity. Lastly, it is also possible that individuals who do not actually consider themselves Christian completed the study as there was no validity check for religious affiliation. See appendix F for the final positive, negative, and neutral primes developed in this study and used in Study 3.

\section{Study 3}

The purpose of Study 3 (a two-part study) was to replicate the results of Study 2 and to determine if activating differing beliefs about God, via the six-verse primes created in the above studies, impacted thought-action fusion and scrupulosity symptoms.

We hypothesized that, following the prime, groups would differ in 1) the negativity/positivity of their beliefs about God, 2) their responses to the thought-induction task, and 3) self-reported levels of scrupulosity and thought-action fusion. Specifically, we expected individuals in the negative prime group to have the most negative and least positive beliefs about God, the most negative responses to the thought- induction task (i.e., higher levels of anxiety, stronger moral unacceptability, stronger desires to cancel out effects of task, etc.), and the highest self-reported levels of scrupulosity and thought-action fusion. We did not expect differences between individuals in the neutral and positive prime groups. Participants were 
compensated one dollar for completing the first part of the study (approximately 15 minutes) and three dollars for completing the second part of the study (approximately 15 minutes).

\section{Study 3 Measures}

\section{Study 3 Methods}

Demographics. Relevant demographic information such as gender, age, ethnicity, and religious affiliation was collected. See Appendix A for full list of demographic questions. See Table 3 .

Participants. Participants identifying as Christian, aged 18 or older, from the United States, and able to read English were recruited through TurkPrime (an Internet-based platform for crowdsourcing that allows researchers to conduct longitudinal research) to participate in this study. Individuals who completed the first two studies were not eligible for this study. See Table 3.

Mood Measure. Participants were asked to rate how positively and negatively they were feeling on a scale of 0 ("not very") to 7 ("very") at that moment. We included these items in the second session of the study to control for any pre-task mood differences between conditions.

Relationship with God. Participants were asked to rate their self-reported relationship with God from 1 ("very bad") to 5 ("very good") during the first session of this study to test for differences in self-reported relationship with God between conditions.

Penn Inventory of Scrupulosity-State. A modified version of the Penn Inventory of Scrupulosity used in previous research (PIOS; Fergus \& Rowatt, 2015; Abramowitz et al., 2002) was used to reflect state-like (verses trait-like) scrupulosity symptoms. The modified PIOS is a 15-item self-report measure utilized in previous research on scrupulosity (Fergus \& Rowatt, 2015). On a scale of 1 ("very slightly or not at all") to 5 ("extremely"), individuals rate how 
much they are currently experiencing the symptoms described in the items. Modified PIOS scores range from 0 to 75 . The modified PIOS was administered during the first session of this study as a baseline measure of scrupulosity symptoms and at the end of the second session of this study to test the effects of the God Belief primes on scrupulosity symptoms (baseline Cronbach's $\alpha=.95$; second session Cronbach's $\alpha=.95$ ).

Santa Clara Strength of Religious Faith Questionnaire. The Santa Clara Strength of Religious Faith Questionnaire (SCRFQ; Plante \& Boccaccini, 1997a,b) is a 10-item self-report scale measuring religiosity. On a scale of 1 ("strongly disagree") to 4 ("strongly agree"), individuals rate their agreement with the items. Scores range from 10 to 40 . The convergent validity of the SCRFQ has been demonstrated through correlations between the SCRFS and other religiosity measures, including with the Intrinsic Religious Motivation Scale (IRMS; r= .69-.82) (Plante et al, 1999), and the factor structure of the SCRFS has been confirmed through confirmatory factor analysis (Lewis et al., 2001). The SCRFS was administered during the first session of this study to test for differences in religiosity between conditions (Cronbach's $\alpha=.92$ ).

Thought-Action Fusion Scale. The Thought-Action Fusion Scale (TAFS; Shafran et al., 1996) is a 19-item self-report questionnaire evaluating beliefs about the importance of thoughts. The TAFS has three subscales: Moral, Likelihood-other, and Likelihood-self. Moral TAF is the belief that thoughts and actions are morally equivalent (e.g., "Having a blasphemous thought is almost as sinful to me as a blasphemous action."). Likelihood-self TAF is the belief that thinking about harm coming to the self increases the probability of the harm actually happening (e.g., "If I think of myself being injured in a fall, this increases the risk that I will have a fall and be injured."). Likelihood-other TAF is the belief that thinking about harm happening to others increases the probability of harm happening to others (e.g., "If I think of a relative/friend being 
in a car accident, this increases the risk that that he/she will have a car accident."). Agreement with each item is based on a 0 ("strongly disagree") to 4 ("strongly agree") rating scale.

Convergent validity has been established by computing correlations between the TAFS subscales and the MOCI-checking subscale for people with obsessions ( $\mathrm{r}=.31-.38)$ and the Total TAF scale and the OCI-R (r=.38) (Shafran et al., 1996; Meyer \& Brown, 2013). The Likelihood-self and Likelihood-other subscales were collapsed into one subscale (TAF-L) for this study, as done by Nelson et al. (2006) to streamline analyses because our hypotheses did not differ between the likelihood-self and other subscales. The TAFS was administered during the first session of this study and at the end of the second session of this study to determine how beliefs about God affected moral and likelihood thought-action fusion (TAFS Total baseline Cronbach's $\alpha=.94$ : TAFS Total second session Cronbach's $\alpha=.95$, TAFS).

Intolerance of Uncertainty Scale-Short Form. The Intolerance of Uncertainty Scale-Short Form (IUS-12; Carleton et al., 2007) is a 12-item self-report scale assessing need for certainty. Individuals rate their agreement with items on a scale of 1 ("not at all characteristic of me") to 5 ("entirely characteristic of me"). The IUS was administered during the first session of this study as a baseline measurement of intolerance of uncertainty (Cronbach's $\alpha=.92$ ).

Concepts of God Checklist. On a scale of 1 ("strongly disagree") to 5 ("strongly agree"), participants rated how well they believed various adjectives described God (modified from Siev et al., 2011). This scale is comprised of two subscales: Positive Concepts of God and Negative Concepts of God (Siev et al., 2011). Six words are included on the positive subscale: peaceful, kind, comforting, gentle, compassionate, and loving. The six words comprising the negative subscale are punishing, fearsome, terrifying, jealous, angry, and vengeful. A composite average score is created for both the negative and positive subscales (Siev et al., 2011). The Concepts of 
God Checklist was administered to replicate findings from Study 2 and as a manipulation check in session 2 of this study (Positive Concepts of God subscale Cronbach's $\alpha=.98$; Negative Concepts of God subscale Cronbach's $\alpha=.93$ ).

\section{God Belief Prime}

In the second session of this study, participants randomly received the positive, negative, or neutral six-verse prime designed to activate positive, negative, or neutral beliefs about God (developed in Studies 1 and 2; see Appendix F).

Participants were instructed to read the prime they were presented with slowly and carefully, thinking about what each verse in the prime meant for three minutes. If they finished reading the prime before time expired, they were instructed to read the verses again, spending additional time thinking about the meaning of the verses. As a validity check, at the end of the second session, participants answered three questions about the content of the verses they read. Participants needed to correctly answer two of the three comprehension questions to be retained for data analysis. Thought Induction Task

Participants completed a thought-induction task (modified from Berman et al., 2011). First, they rated their current anxiety from 0 ("not at all") to 100 ("extremely anxious") using a visual analogue scale (VAS). Participants were then shown the sentence "I hate God" written on the computer monitor. Participants were asked to type the sentence. After typing the sentence, participants were told to close their eyes and imagine the sentence being true for 30 seconds. Using the 0 to $100 \mathrm{VAS}$, participants then rated (a) their current anxiety, (b) the perceived likelihood of actually hating God, (c) the morality of their thinking and writing "I hate God," and (d) their desire to reduce or cancel the effects of typing and thinking "I hate God." The task was 
administered in session 2 of this study to determine how God belief primes affected responses to an intrusive thought relevant to scrupulosity.

\section{Study 3 Procedure}

This was a two-session study conducted over the Internet using Turkprime. In session 1, following consent, participants completed the PIOS, IUS, TAFS, and SCRFS in a randomized order to assess baseline scrupulosity, intolerance of uncertainty thought-action fusion, and religiosity, respectively. Approximately 14 days ( $M=14.11, S D=2.26$, Range=13-32 days) after session 1 was completed, participants completed session 2 of the study. Participants were randomly assigned to the positive, negative, or neutral God belief primes described above. After completing the prime, participants completed the thought-induction task and indicated their VAS ratings. Once the thought-induction task was finished, participants completed the PIOS and the TAFS in a randomized order. Lastly, participants answered three comprehension questions related to the verses they read as a validity check. If participants did not complete session 2 of this study within three days of receiving the first invitation, they received an email reminder. A second reminder email was sent nine days after the first reminder email.

\section{Study 3 Results}

Power Analysis. Sample size $(N=255)$ was determined using $\mathrm{G} *$ Power analysis software (Faul et al., 2007). To be conservative, we estimated a small effect size for our primes' impact on the thought-induction task (the main dependent variable of interest in this study).

Data Reduction. Two hundred and sixty-eight participants completed the study. Due to an experimenter error, several participants completed the first and second sessions of the study multiple times. Two participants completed part one of the study multiple times, and 12 
participants completed part two of the study multiple times. Only the participants' first case was retained. Of the 268 participants, 51 were excluded from analyses ( $n=2$ completed part two multiple times and it was unclear which case to retain; $n=45$ participants only completed session 1 of the study; $n=3$ failed the validity check). There were no significant differences in baseline religiosity, thought-action fusion, or intolerance of uncertainty between those who were included and were excluded from analyses. There was a significant difference in scrupulosity scores between those who completed part 1 of the study $(M=33.07, S D=14.34)$ and those who completed parts 1 and $2(M=27.41, S D=12.29)$ of the study $(p=.016)$. Note that we retained participants who skipped writing "I hate God" and completed the rest of the survey (n=13) and those who stopped directly after they were asked to type "I hate God," even though they did not do validity checks $(\mathrm{n}=8)$.

Data transformation. To correct for skew and kurtosis, the likelihood item following the thought-induction task was transformed using a square root transformation. The other variables associated with the thought-induction task (post-test anxiety, morality of writing "I hate God," and desire to complete compulsive behavior) were also transformed using a square root transformation for consistency in data analysis. In addition, the morality of writing "I hate God" variable was reverse coded for consistency in data analysis. VIF and tolerance values were within recommended ranges. There were no outliers for any of the variables.

Demographics. Participants included 117 females (53.9\%) and 100 males (46.1\%) with an average age of $42(M=42.05, S D=13.33$, range=19-73). Approximately $80 \%$ of the sample identified as White $(n=175)$ followed by Black $(12.15 \% ; n=23)$ and East Asian $(2.8 \% ; n=6)$. Overall, our sample was well educated with approximately $64 \%(\mathrm{n}=139)$ of our sample having a college or advanced (master's and/or PhD) degree (12\% high school degree, $23.5 \%$ some 
college). The sample consisted primarily of individuals self-identifying as Protestant $(n=119)$ and Catholic $(n=79)$. There were no group differences in age, ethnicity, race, gender, or religious affiliation. See Table 4 for demographic dataThere were also no baseline group differences in scrupulosity $\left(F_{(2,214)}=.64, p=.53\right.$, partial $\left.\eta_{2}=.00\right)$, total thought-action fusion $\left(F_{(2,214)}=.17, p=.85\right.$, partial $\left.\eta_{2}=.00\right)$, likelihood thought-action fusion $\left(F_{(2,214)}=.57, p=.56\right.$, partial $\left.\eta_{2}=.00\right)$, self-reported relationships with $\operatorname{God}\left(F_{(2,214)}=.84, p=.43\right.$, partial $\left.\eta_{2}=.00\right)$, intolerance of uncertainty $\left(F_{(2,214)}=.36\right.$, $p=.70$, partial $\left.\eta_{2}=.00\right)$, religiosity $\left(F_{(2,214)}=.39, p=.68\right.$, partial $\left.\eta_{2}=.00\right)$, and positive $\left(F_{(2,214)}=75\right.$, $p=.47$, partial $\left.\eta_{2}=.00\right)$ or negative $\left(F_{(2,214)}=.62, p=.54\right.$, partial $\left.\eta_{2}=.00\right)$ mood between conditions. See Table 5 for baseline descriptive data

Manipulation check. To determine if the primes successfully modified participants’ beliefs about God, a repeated-measures ANOVA with prime condition (positive, negative, or neutral verses) as a between-subjects factor and Concepts of God subscale (positive, negative) as a within-subjects factor was conducted. Similar to Study 2, there was a significant interaction between beliefs about God and condition $\left(F_{(2,214)}=64.95, p<.001\right.$, partial $\left.\eta_{2}=.38\right)$.

To interpret this interaction, separate one-way ANOVAs for the positive and negative Concepts of God subscales were conducted, with prime condition (positive, negative, and neutral verses) as a between-subjects variable. For the Positive Concepts of God subscale, the ANOVA indicated significant differences in positive beliefs about God between condition $(F(2,214)=35.87$, $p<.001$, partial $\eta_{2}=.25$ ). Tukey post-hoc analyses revealed that positive beliefs about God were significantly different between the positive $(M=27.71, S D=3.12)$ and the negative $(M=20.53$, $S D=8.27)$ conditions $(p<.001)$ and between the negative $(M=20.53, S D=8.27)$ and the neutral $(M=26.41, S D=3.20)$ conditions $(p<.001)$. There was no significant difference between the neutral $(M=26.41, S D=3.20)$ and positive condition $(M=27.72, S D=3.12 ; p=.31)$ For the Negative 
Concepts of God subscale, there were significant differences in negative beliefs about God between conditions $\left(F_{(2,214)}=61.98, p<.001\right.$, partial $\left.\eta_{2}=.37\right)$. Tukey post-hoc analyses revealed significant differences in negative beliefs about God between the negative $(M=20.19, S D=6.38)$ and the positive $(M=10.03, S D=4.72)$ conditions $(p<.001)$, between the negative $(M=20.19$, $S D=6.38)$ and the neutral $(M=13.19, S D=5.56)$ conditions $(p<.001)$, and between the positive $(M=20.19, S D=6.38)$ and neutral $(M=13.19, S D=5.56)$ conditions $(p=.002)$. See Figures 1 and 2.

To determine if the primes impacted state anxiety, we conducted a post-hoc one-way ANOVA with prime condition (positive, negative, or neutral verses) as a between-subjects variable and anxiety following the prime as the dependent variable. There was a significant difference in anxiety between condition $\left(F_{(2,215)}=4.28, p=.015\right.$, partial $\left.\mathrm{y}_{2}=.04\right)$. Tukey post hoc analyses indicated a significant difference in anxiety between the positive $(M=17.21, S D=20.13)$ and negative prime $(M=28.87, S D=26.74)$ condition $(p=.011)$.

Thought induction task. A MANOVA with prime condition (positive, negative, and neutral) as the between-subjects variable and responses to the thought-induction task (post-test anxiety, perceived likelihood of hating God, morality of writing "I hate God," and desire to perform compulsive behavior) as the dependent variables was conducted to determine how the prime impacted performance on the thought-induction task. Box's M was not significant $\left(F_{(20,}\right.$ $145612.90)=23.51, p>.05)$. Thus, Wilks' Lambda was used to assess main effects. There were no significant difference in responses to the thought-induction task between conditions $(F(8,396)=.72$, $p=.675$, partial $\left.y_{2}=.01\right)$. See Figure 3 .

Change in PIOS scores. A repeated measures ANOVA with prime condition (positive, negative, or neutral) as the between-subjects factor and two within-subjects variables (baseline PIOS and post-test PIOS scores) was conducted to determine if the prime impacted participants' 
symptoms of scrupulosity. There was no significant difference in change in PIOS score between condition $\left(F_{(2,203)}=.06, p=.399\right.$, partial $\left.\eta_{2}<.001\right)$. See Figure 2 .

Change in TAFS. Three repeated measures ANOVAs with prime condition (positive, negative, and neutral) as the between-subjects factor and two within-subjects variables (baseline TAFS total, moral, or likelihood and post-test TAFS, total, moral, or likelihood scores) were conducted to determine if the prime impacted participants' symptoms of thought-action fusion. There was no significant difference in change in TAFS score for the total $(F(2,203)=.76, p=.470$, partial $\left.\eta_{2}=.00\right)$, moral $\left(F_{(2,203)}=1.87 p=.156\right.$, partial $\left.\eta_{2}=.02\right)$, or likelihood $\left(F_{(2,203)}=.14, p=.87\right.$, partial $\eta_{2}=.00$ subscales of the TAFS. See Figure 3.

Condition effects on the dependent variables of the thought-induction task and scores on the PIOS and TAFS remained nonsignificant when religiosity, intolerance of uncertainty, or selfreported relationship with God were included as covariates in analyses.

Exploratory post-hoc analyses. Bivariate correlations were computed to explore relationships between scrupulosity, religiosity, and beliefs about God (see Table 7). There was a significant negative correlation between positive and negative beliefs about God $(r(215)=-.63$, $p<.001)$. There was a significant positive correlation between positive beliefs about God and religiosity $(r(215)=.24, p<.001)$. There was also a significant positive correlation between religiosity and self-reported relationship with $\operatorname{God}(r(215)=.66, p<.001)$. Other significant correlations were found between religiosity and baseline total TAFS score $(r(215)=.33, p<.001)$ and between religiosity and baseline moral TAFS score $(r(215)=.33, p<.001)$. The correlation between negative beliefs about God and baseline symptoms of scrupulosity was not significant $(r(215)=.07, p=.294)$. Finally, there was a significant positive correlation between self-reported 
relationship with God and age $(r(215)=.17, p=.015)$ and a significant negative correlation between scrupulosity symptoms and age $(r(215)=-.27, p<.001)$.

\section{Study 3 Discussion}

The purpose of Study 3 was to replicate the results of Study 2 and to determine how differing beliefs about God impacted a scrupulosity-relevant task and measures of thought-action fusion and scrupulosity. Results from Study 2 were replicated; participants in the negative prime condition rated God significantly more negatively and less positively than those in the positive and neutral prime conditions. This provides further evidence that differing beliefs about God can be activated with even brief primes. However, our hypotheses that participants in the negative prime condition would have more negative responses to the thought-induction task and have elevated scores on self-report measures of thought-action fusion and scrupulosity was not supported.

\section{Overall Discussion}

The overall purpose of this series of studies was to develop primes that could activate differing beliefs about God and to determine if these primes impacted a scrupulosity-relevant task and measures. The purpose of Study 1 was to create groupings of Bible verses that could be used as primes to activate positive, negative, and neutral beliefs about God. The purpose of Study 2 was to determine if the primes created in Study 1 could activate differing beliefs about God. Lastly, the purpose of Study 3 was to replicate findings from Study 2 and to determine how activated negative beliefs about God impacted a task relevant to scrupulosity and measures of thought-action fusion and scrupulosity. The negative prime was able to activate participants' negative beliefs about God. In Studies 2 and 3, individuals in the negative prime condition endorsed less positive beliefs of God and more negative views of God than those in the positive 
and neutral prime conditions. Post hoc analyses indicated that participants in the negative condition also experienced elevated state anxiety after the God belief prime. However, our hypotheses that individuals in the negative prime condition would have the most negative reactions to the thought-induction task and would experience increases in thought-action fusion or scrupulosity symptoms after the God belief prime were not supported.

Because there was often no significant difference in positive beliefs about God between the neutral and positive conditions, it is unclear if the positive prime activated positive beliefs about God. Including a baseline measure of beliefs about God in future research will be important to tease apart the effects of the neutral and positive primes on activating beliefs about God.

The above results indicate that differing beliefs about God may be activated with even a relatively brief prime. Given that positive beliefs about God are overall associated with better mental health outcomes, including for obsessions and compulsions, and that negative beliefs about God negatively impact obsessions, compulsions, paranoia, social anxiety, and self-esteem (Silton, et al., 2013; Inzlicht \& Tullett, 2010; Benson \& Spika, 1973), it is encouraging that even activating neutral (and not necessarily positive) beliefs about God resulted in a significant difference in negative beliefs about God between conditions. The current research provides preliminary evidence that differing beliefs about God can be activated, and thus treatments that specifically help individuals spend less time attuning to negative descriptors of God and more time attuning to positive (or possibly neutral) attributes of God may one day be used in treatment of scrupulosity to help patients modify their negative beliefs about God while strengthening their neutral and positive beliefs about God.

Although participants in the neutral condition endorsed positive beliefs about God between that of participants in the positive and negative prime conditions (positive > neutral > negative), 
this difference was not significant in Study 2 or 3. In Study 2, there was also not a significant difference in negative beliefs about God between the positive and neutral condition. Thus, it is unclear if the positive condition activated positive beliefs about God. It is possible that the negative prime was activating negative beliefs about God while the neutral and positive prime activated more neutral beliefs about God. It is also possible that the Bible verses selected for the neutral prime were being interpreted in a positive or negative manner depending on participants' perceived relationship with God or their baseline/previous beliefs about God. Future research should explore the possibility of developing a prime that can definitively activate positive beliefs about God and the plausibility of people having truly neutral beliefs about God.

Post-hoc analyses revealed that individuals in the negative prime condition experienced significantly higher anxiety following the prime than those in the positive condition. This suggests that negative beliefs about God may play a role in state anxiety. Perhaps reading Bible verses that portrayed God in a negative manner (i.e., angry and judgmental) prompted anxiety by reminding participants of God's expectations for behavior and possible punishment(s) for disobeying. It is also possible that reading Bible verses that portrayed God in a positive manner (i.e., loving and caring) reduced anxiety by reminding participants that God is merciful and forgives one's sins.

The primes did not significantly impact variables related to the thought-induction task, thought-action fusion, or symptoms of scrupulosity. It is possible that beliefs about God are unrelated to thought-action fusion or scrupulosity. However, this seems unlikely. Previous research demonstrates elevated levels of moral thought-action fusion in religious-specifically Protestant-individuals (Siev \& Cohen, 2007; Siev et al., 2010; Berman, et al.,2010; Rassin \& Koster, 2003). It is also unlikely that beliefs about God are unrelated to scrupulosity symptoms as scrupulosity focuses on fear of sin and fear of punishment from God (Abramowitz et al., 2002). 
Instead, in order for the primes to effectively impact the thought-induction task or responses on the TAFS or PIOS, the dosage of the primes may need to be modified — via a differing number of verses or repeated exposure to the verses. In addition, the target sentence of the thought-induction task may not have been strong enough for differences between conditions to emerge. For all conditions, the average self-reported anxiety after writing the sentence, "I hate God" was low (positive: $M=37.40, S D=30.98$; neutral $M=36.35, S D=26.75$; negative; $M=37.93, S D=28.31$ ). It is also possible that other important aspects of one's beliefs about God, such as feelings of guilt or letting God down, are implicated in scrupulosity. If this is true, simply having more positive, negative, or neutral beliefs about God may not impact one's reaction to the thought-induction task or increase symptoms of thought-action fusion and scrupulosity. Thus, future research should examine how more nuanced aspects of individual's beliefs about God impact scrupulosity symptoms. Lastly, the nonsignificant results could be partially due to the measures we selected. The TAFS is a trait measure and has not been validated as an effective measure to capture statelike changes in the construct. Similarly, although the measure of scrupulosity symptoms was designed to reflect state changes in symptoms and has been used in previous research (Fergus \& Rowatt, 2015), limited psychometric properties of the measure have been established. Future research should examine the appropriateness of the TAFS and modified PIOS for research on state changes in these constructs.

This study is not without its limitations. First, although the primes were able to activate negative beliefs about God, it is unclear how long these activated beliefs persist. In addition, the manipulation used to induce negative beliefs about God may not have been strong enough to impact PIOS, TAFS, post-task anxiety, post-task morality, or post-task compulsive scores. Future research should examine how different doses of the prime, such as longer primes or 
repeated exposures to verses, impact scrupulosity symptoms. In addition, a nonclinical sample was used in this study, and it is possible that a diagnosed OCD sample may have important uncaptured characteristics impacting performance on the thought-induction task and scrupulosity symptoms that we cannot evaluate with the use of our nonclinical sample. Relatedly, the average score on the Penn Inventory of Scrupulosity was below the average reported by Huppert et al. for a sample of patients with scrupulosity, making it possible that this sample had fewer symptoms of scrupulosity than necessary to impact results. Participants also completed this study online, so it is possible that participants were not properly completing the prime or thought-induction task, impacting the results of this study. Relatedly, because participants simply had to self-identify as Christian and this criterion was advertised to participants in all three studies, it is possible that individuals may not have been honest about their religious affiliation. However, the mean religiosity score of the sample collected in Study 3 was 31, which is just below the advised cutoff score of 33 (Plante \& Boccaccini, 1997a; Plante \& Boccaccini, 1997b), indicating this sample had moderate to strong religiosity. Lastly, although the sample size was large and diverse, a larger and more racially diverse sample would increase generalizability.

Although the primes did not impact performance on the thought-induction task or scores on the PIOS and TAFS, the ability of the negative prime to activate negative beliefs about God is an important step for research on the impact of religion on mental health. To our knowledge, this is the only validated prime that directly activates people's beliefs about God to be more negative. The results of this study highlight the ability to activate people's differing beliefs about God, indicating the possibility of targeting and modifying negative beliefs about God in psychological interventions. Although exploratory, the ability of the negative prime to impact state-anxiety also suggests that negative beliefs about God may impact the development or maintenance of 
anxiety in individuals that self-identify as Christian. Future research should continue to explore how negative, positive, and neutral beliefs about God can be modified and impact symptoms of scrupulosity. 


\section{References}

Abramowitz, J.S., \& Jacoby, R. (2014). Scrupulosity: A cognitive-behavioral analysis and implications for treatment. Journal of Obsessive-Compulsive and Related Disorders, 3(2), 140-149. https://doi.org/10.1016/j.jocrd.2013.12.007.

Abramowitz J.S., Khandker, M., Nelson, C., Deacon, B., \& Rygwall R. (2005). The role of cognitive factors in the pathogenesis of obsessive-compulsive symptoms: A prospective study. Behaviour Research and Therapy, 44, 1361-1374. https://doi.org/ 10.1016/j.brat.2005.09.011

Abramowitz, J. S., Huppert, J. D., Tolin, D. F., \& Cahill, S. P. (2002). Religious obsessions and compulsions in a non-clinical sample: the Penn Inventory of Scrupulosity (PIOS). Behaviour Research and Therapy, 40(7), 825-838. https://doi.org/10.1016/s00057967(01)00070-5.

Akhtar, S., Wig, N. N., Varma, V. K., Perhsad, D., \& Verma, S. K. (1978). Socio-cultural and clinical determinants of symptomatology in obsessional neurosis. International Journal of Social Psychiatry, 24, 157-162. https://doi.org/ 10.1177/002076407802400301.

Alonso, P., Menchon, J. M., Pifarre, J., Mataix-Cols, D., Torres, L., Salgado, P., et al. (2001). Long-term follow-up and predictors of clinical outcome in obsessive-compulsive patients treated with serotonin reuptake inhibitors and behavioral therapy. Journal of Clinical Psychiatry, 62, 535-540. https://doi.org/ 10.4088/jcp.v62n07a06.

American Psychiatric Association (2013). Diagnostic and statistical manual of mental disorders (5th ed.). Washington, DC: American Psychiatric Association.

Benson, P., \& Spilka, B. (1973). God image as a function of self-esteem and locus of control. 
Journal for the Scientific Study of Religion, 12(3), 297-310. https://doi.org/ $10.2307 / 1384430$.

Berman, N., Abramowitz, J., Wheaton, M., Pardue, C., \& Fabricant, L. (2011). Evaluation of an In Vivo Measure of Thought-Action Fusion. Journal of Cognitive Psychotherapy, 25, 155-164. https://doi.org/10.1891/0889-8391.25.2.155.

Berman, N., Stark, A., Ramsey, K., Cooperman, A., \& Abramowitz, J. (2014). Prayer in Response to Negative Intrusive Thoughts: Closer Examination of a Religious Neutralizing Strategy. Journal of Cognitive Psychotherapy, 28, 87-100. https://doi.org/10.1891/0889-8391.28.2.87.

Bradley, M., \& Lang, P. (1994). Measuring Emotion: The self-assessment manikin and the semantic differential. Journal of Behavior Therapy and Experimental Psychiatry, 25(1), 49-59. https://doi.org/10.1016/0005-7916(94)90063-9.

Buhr, K., \&Dugas, M. (2009). The role of fear of anxiety and intolerance of uncertainty in worry: An experimental manipulation. Behaviour Research and Therapy, 47, 215-223. https://doi.org/10.1016/j.brat.2008.12.004

Carleton, R., Norton, P., \& Asmundson, G. (2007). Fear of the unknown: A short version of the Intolerance of Uncertainty Scale. Journal of Anxiety Disorders, 21, 105-117.

Cohen, A., \& Rozin, P. (2001). Religion and the morality of mentality. Journal of Personality and Social Psychology, 81, 697-710. https://doi.org/10.1016/j.janxdis.2006.03.014.

Egrilmez, A., Gulseren, L., Gulseren, S., \& Kultur, S. (1997). Phenomenology of obsessions in a Turkish series of OCD patients. Psychopathology, 30, 106-110. https://doi.org/10.1159/000285037.

Eisen, J. L., Goodman, W. K., Keller, M. B., Warshaw, M. G., DeMarco, L. M., Luce, D. D., \& 
Rasmussen, S. A. (1999). Patterns of remission and relapse in obsessive-compulsive disorder: A 2-year prospective study. Journal of Clinical Psychiatry, 60, 346-351. https://doi.org/ 10.4088/jcp.v60n0514.

Faul, F., Erdfelder, E., Lang, A.-G,. \& Buchner, A. (2007). G*Power 3: A flexible statistical power analysis program for the social, behavioral, and biomedical sciences. Behavior Research Methods, 39, 175-191.

Fergus, T., \& Rowatt, W. (2015). Uncertainty, god, and scrupulosity: Uncertainty salience and priming god concepts interact to cause greater fear of sin. Journal of Behavior Therapy and Experimental Psychology, 46, 93-98. https://doi.org/10.1016/j.jbtep.2014.09.003.

Ferrao, Y. A., Shavitt, R. G., Bedin, N. R., Mathis, M. E., Lopes, A. C., Leonardo, F. F., et al. (2006). Clinical features associated to refractory obsessive-compulsive disorder. Journal of Affective Disorders, 94, 191-209. https://doi.org/ 10.1016/j.jad.2006.04.019.

Flannelly, K., Galek, K., Ellison, C., \& Koenig, H. (2010). Beliefs about God, Psychiatric Symptoms, and Evolutionary Psychiatry. Journal of Religion and Health, 49, 246-261. https://doi.org/10.1007/s10943-009-9244-z

Foa, E. B., \& Kozak, M. J. (1995). DSM-IV field trial: obsessive-compulsive disorder. American Journal of Psychiatry, 152, 90-96. https://doi.org/ 10.1176/ajp.152.1.90.

Gibbs, N.A. (1996). Nonclinical populations in research on obsessive-compulsive disorder: a critical review. Clinical Psychology Review, 16, 729-773. https://doi.org/ 10.1016/S02727358(96)00043-8

Hodes, R., Cook, E. W. III, \& Lang, P. J. (1985). Individual differences in autonomic response: conditioned association or conditioned fear? Psychophysiology, 22,545-560. https://doi.org/ 10.1111/j.1469-8986.1985.tb01649.x. 
Inzlicht, M., \& Tullet, A. M. (2010). Reflecting on God: religious primes can reduce neuropsychological response to errors. Psychological Science, 21, 1184-1190. https://doi.org/ 10.1177/0956797610375451.

Lang, P.J. (1980). Behavioral treatment and bio-behavioral assessment: Computer applications. In J.B. Sidowski, J.H. Johnson, \& T.A. Williams, (Eds.), Technology in mental health care delivery systems (pp. 119-137). Norwood, N.J: Ablex.

Lewis, C.A., Shevlin, M., McGuckin, C., Navrátil, M. (2001). The Santa Clara Strength of Religious Faith Questionnaire: Confirmatory factor analysis. Pastoral Psychology, 49, 379-384. https://doi.org/10.1023/A:1010370728546

Mahgoub, O. M., \& Abdel-Hafeiz, H. B. (1991). Pattern of obsessive-compulsive disorder in Eastern Saudi Arabia. The British Journal of Psychiatry, 158, 840-842. https://doi.org/ 10.1192/bjp.158.6.840.

Mataix-Cols, D., Marks, I. M., Greist, J. H., Kobak, K. A., \& Baer, L. (2002). Obsessivecompulsive symptom dimensions as predictors of compliance with and response to behaviour therapy: Results from a controlled trial. Psychotherapy and Psychosomatics, 71, 255-262. https://doi.org/10.1159/000064812.

McKay, R., Efferson, C., Whitehouse, H., \& Fehr, E. (2011). Wrath of God: religious primes and punishment. Proceedings of the Royal Society B: Biological Sciences, 278, 1858-1863. https://doi.org/10.1098/rspb.2010.2125.

Meyer, J., \& Brown, T. (2013). Psychometric Evaluation of the Thought-Action Fusion Scale in a Large Clinical Sample. Assessment, 20, 764-775. https://doi.org.10.1177/1073191112436670 
Miller, C., \& Hedges, D. (2008). Scrupulosity disorder: An overview and introductory analysis. Journal of Anxiety Disorders, 22, 1042-1058. https://doi.org/10.1016/j.janxdis.2007.11.004

Muris, P., Meesters, C., \& Rassin, E. (2001). Thought-action fusion and anxiety disorder symptoms in normal adolescents. Behavior Research and Therapy, 39, 843-852. https://doi.org/ 10.1016/s0005-7967(00)00077-2.

Nelson, E., Abramowitz, J., Whiteside, S., \& Deacon, B. (2006). Scrupulosity in patients with obsessive- compulsive disorder: Relationship to clinical and cognitive phenomena. Anxiety Disorders, 20, 1071-1086. https://dio.org/10.1016/j.janxdis.2006.02.001

Okasha, A. (2004). OCD in Egyptian adolescents: The effect of culture and religion. Psychiatric Times, 21, 1-5.

Pirutinsky, S., Siev, J., \& Rosmarin, D. (2015). Scrupulosity and implicit and explicit beliefs about God. Journal of Obsessive-Compulsive Related Disorders, 6, 33-38. https://doi.org/10.1016/j.jocrd.2015.05.002

Plante, T.G.; Boccaccini, M. (1997a) The Santa Clara Strength of Religious Faith Questionnaire. Pastoral Psychology, 45, 375-387.

Plante, T.G.; Boccaccini, M. (1997b) Reliability and validity of the Santa Clara Strength of Religious Faith Questionnaire. Pastoral Psychology, 45, 429-437. https://doi.org/10.1007/BF02310643.

Plante, T., Yancey, S., Sherman, A., \& Guertin, M. (1999). Further Validation for the Santa Clara Strength of Religious Faith Questionnaire. Pastoral Psychology, 48(1), 11-21. https://doi.org/10.1023/A:1021950628088. 
Rachman, S. (1997). A cognitive theory of obsessions. Behaviour Research and Therapy, 35, 793-802. https://doi.org/ 10.1016/s0005-7967(97)00040-5.

Rachman, S. (1998). A cognitive theory of obsessions: Elaborations. Behaviour Research and Therapy, 36(4), 385-401. https://doi.org/10.1016/s0005-7967(97)10041-9

Rachman, S. (2002). A cognitive theory of compulsive checking. Behaviour Research and Therpay, 40. https://doi.org/ 10.1016/s0005-7967(01)00028-6.

Rachman, S., \& DeSilva, A. (1978). Abnormal and normal obsessions. Behaviour Research and Therapy, 16, 233-248. https://doi.org/ 10.1016/0005-7967(78)90022-0.

Rassin, E., \& Koster, E. (2003). The correlation between thought-action fusion and religiosity in a normal sample. Behaviour Research and Therapy, 41(3), 361-368. https://doi.org/ 10.1016/s0005-7967(02)00096-7.

Rassin, E., Muris, P., \& Schmidt, H. (2000). Relationships between thought-action fusion, thought suppression and obsessive- compulsive symptoms: a structural equation modeling approach. Behaviour Research and Therapy, 38, 889-897. https://doi.org/10.1016/s0005-7967(99)00104-7.

Rufer, M., Grothusen, A., Mab, R., Peter, H., \& Hand, I. (2005). Temporal stability of symptom dimensions in adult patients with obsessive-compulsive disorder. Journal of Affective Disorders, 88, 99-102. https://doi.org/ 10.1016/j.jad.2005.06.003.

Shafran, R., Thordarson, D., \& Rachman, S. (1996). Thought-Action Fusion in Obsessive Compulsive Disorder. Journal of Anxiety Disorders, 10(5), 379-391. https://doi.org/10.1016/0887-6185(96)00018-7. 
Silton, N.R., Flannelly, K.J., Galek, K., Ellison, C.G. (2014). Beliefs about God and mental health among American adults. Journal of Religious Health, 53, 1285-1296. https://doi.org/10.1007/s10943-013-9712-3.

Sherman, A.C., Plante, T.G., Simonton, S., Adams, D., Burris, K., Harbison, C. (1999). Further Validation for the Santa Clara Strength of Religious Faith Questionnaire. Pastoral Psychology, 48, 129-142. https://doi.org/10.1023/A:1021950628088.

Shooka, A., Al-Haddad, M. K., \& Raees, A. (1998). OCD in Bahrain: A phenomenological profile. International Journal of Social Psychiatry, 44, 147 -154. https://doi.org/ 10.1177/002076409804400207.

Siev, J., Baer, L., \& Minichiello, W. (2011, December). Obsessive-compulsive disorder with predominantly scrupulous symptoms: clinical and religious characteristics. Journal of Clinical Psychology, 67(12), 1188-1196. https://doi.org/ 10.1002/jclp.20843.

Siev, J., Chambless, D. L., \& Huppert, J. D. (2010). Moral thought-action fusion and Scrupulosity in OCD OCD symptoms: The moderating role of religious affiliation. Journal of Anxiety Disorders, 24(3), 309-312. https://doi.org/10.1016/j.janxdis.2010.01.002.

Siev, J. C., \& Cohen, A. B. (2007). Is thought-action fusion related to religiosity? Differences between Christians and Jews. Behaviour Research and Therapy 45(4), 829-837. https://doi.org/10.1016/j.brat.2006.05.001.

Silton, N., Flannelly, K., Galek, K., \& Ellison, C. (2014). Belief About God and Mental Health Among American Adults. Journal of Religious Health, 53, 1285-1296. https://doi.org/10.1007/s10943-013-9712-3.

Sumerfeldt L., Antony, M.M, Downie, F., Richter, M.A, \& Swinson, R.P., 1997. Prevalence of 
particular obsessions and compulsions in a clinic sample. Unpublished manuscript.

Tolin, D., Abramowitz, J., Kozak, M., \& Foa, E. (2001). Fixity of belief, perceptual aberration, and magical ideation in obsessive-compulsive disorder. Journal of Anxiety Disorders, 15, 501-510. https://doi.org/ 10.1016/s0887-6185(01)00078-0.

Toburen, T., \& Meier, B. (2010). Priming God-related concepts increases anxiety and task persistence. Journal of Social and Clinical Psychology, 29, 127-143. https://doi.org/10.1521/jscp.2010.29.2.127. 
Table 1

Means and Standard Deviations of Prime Groups for Study 1

\begin{tabular}{|c|c|c|c|c|c|c|c|c|c|c|c|c|}
\hline & & \multicolumn{3}{|c|}{ 5-verses } & \multicolumn{3}{|c|}{ 6-verses } & \multicolumn{3}{|c|}{ 8-Verses } \\
\hline Valence & $6.78(1.76)$ & $5.58(1.23)$ & $4.23(1.72)$ & $6.82(1.75)$ & $5.73(1.25)$ & $4.26(1.72)$ & $7.03(1.64)$ & $5.67(1.91)$ & $3.72(1.94)$ & $7.08(1.52)$ & $5.75(1.18)$ & $3.70(1.93)$ \\
\hline Familiarity & $5.09(2.16)$ & $4.67(2.05)$ & $4.83(2.21)$ & $5.00(2.14)$ & $4.90(2.08)$ & $4.90(2.04)$ & $5.19(2.05)$ & $4.80(1.93)$ & $4.61(2.10)$ & $5.44(1.95)$ & $4.92(1.85)$ & $4.68(2.07)$ \\
\hline Complexity & $3.60(1.80)$ & $3.69(1.85)$ & $3.86(2.01)$ & $3.80(1.80)$ & $3.75(1.72)$ & $3.84(1.87)$ & $3.72(1.82)$ & $3.96(1.82)$ & $3.88(1.69)$ & $3.49(1.84)$ & $3.72(1.73)$ & $3.92(1.83)$ \\
\hline
\end{tabular}


Table 2

Means and Standard Deviations for each Prime on the God Concept Subscale for Study 2

\begin{tabular}{|c|c|c|c|c|c|c|c|c|c|c|c|c|}
\hline & \multicolumn{3}{|c|}{$\begin{array}{l}\text { 3-verses } \\
\mathrm{M}(\mathrm{SD})\end{array}$} & \multicolumn{3}{|c|}{$\begin{array}{l}\text { 5-verses } \\
M(S D)\end{array}$} & \multicolumn{3}{|c|}{$\begin{array}{l}\text { 6-verses } \\
M(S D)\end{array}$} & \multicolumn{3}{|c|}{$\begin{array}{l}\text { 8-Verses } \\
\text { M(SD) }\end{array}$} \\
\hline & Positive & Neutral & Negative & Positive & Neutral & Negative & Positive & Neutral & Negative & Positive & Neutral & Negative \\
\hline $\begin{array}{l}\text { Positive } \\
\text { Concepts }\end{array}$ & $24.89(3.71)$ & $25.95(3.14)$ & $23.42(6.53)$ & $28.24(2.08)$ & $25.38(4.51)$ & $23.00(6.06)$ & $25.95(3.27)$ & $25.21(4.42)$ & $18.90(8.67)$ & $27.42(3.10)$ & $25.30(2.92)$ & $22.24(7.17)$ \\
\hline
\end{tabular}


Table 3

Descriptive Statistics for Study 1

Participants

$(n=48)$

Age [mean (SD) years]

$37.85(13.42)$

Gender [number (\%) male]

$37(77.1 \%)$

Ethnicity [number (\&) nonhispanic]

$40(83.3 \%)$

Race [number (\%) white]

$40(83.3 \%)$

Education [number (\%)]

High School

$8(16.7 \%)$

College Degree

$32(66.7 \%)$

Advanced Degree

$8(16.7 \%)$ 
Table 4

Descriptive Statistics for Study 2

Participants $(n=230)$

Age [mean (SD) years]

$34.30(10.41)$

Gender [number (\%) male]

$132(57.4 \%)$

Ethnicity [number (\&) nonhispanic]

$186(80.9 \%)$

Race [number (\%) white]

$148(64.3 \%)$

Education [number (\%)]

High School

$49(21.3 \%)$

College Degree

$159(69.1 \%)$

Advanced Degree

$22(9.6 \%)$ 
Table 5

Descriptive Statistics for Study 3

\begin{tabular}{|c|c|c|c|}
\hline & Positive Condition & Neutral Condition & Negative Condition \\
\hline Age [mean (SD) years] & $42.45(12.91)$ & $43.14(13.49)$ & $40.54(13.60)$ \\
\hline $\begin{array}{l}\text { Gender [number (\%) } \\
\text { male] }\end{array}$ & $30(42.25 \%)$ & $38(51.35 \%)$ & $32(44.45 \%)$ \\
\hline $\begin{array}{l}\text { Ethnicity [number (\%) } \\
\text { nonhispanic] }\end{array}$ & $67(94.37 \%)$ & $63(85.14 \%)$ & $69(97.18 \%)$ \\
\hline $\begin{array}{l}\text { Race [number (\%) } \\
\text { white] }\end{array}$ & $62(88.57 \%)$ & $65(89.04 \%)$ & $51(71.83 \%)$ \\
\hline \multicolumn{4}{|l|}{ Education } \\
\hline High School & $10(14.08 \%)$ & $11(15.07 \%)$ & $5(6.94 \%)$ \\
\hline Some College & $17(23.94 \%)$ & $16(21.92 \%)$ & $18(25.00 \%)$ \\
\hline College Degree & $41(57.75 \%)$ & $35(47.95 \%)$ & $37(51.39 \%)$ \\
\hline Advanced Degree & $3(4.23 \%)$ & $11(15.07 \%)$ & $12(16.67 \%)$ \\
\hline \multicolumn{4}{|l|}{ Religion } \\
\hline Protestant & $39(54.93 \%)$ & $44(59.46 \%)$ & $36(50.00 \%)$ \\
\hline Catholic & $27(38.03 \%)$ & $23(31.08 \%)$ & $29(40.28 \%)$ \\
\hline Other & $5(7.04 \%)$ & $7(9.46 \%)$ & $7(9.72 \%)$ \\
\hline
\end{tabular}


Table 6

Means and Standard Deviations for Study 3

\begin{tabular}{lccl}
\hline & $\begin{array}{c}\text { Positive } \\
M(S D)\end{array}$ & $\begin{array}{c}\text { Neutral } \\
M(S D)\end{array}$ & $\begin{array}{c}\text { Negative } \\
M(S D)\end{array}$ \\
\hline PIOS (session 1) & $26.62(11.86)$ & $28.75(11.60)$ & $26.91(13.36)$ \\
IUS (session 1) & $32.32(11.26)$ & $32.80(10.35)$ & $31.35(10.06)$ \\
SCSRFQ (session 1) & $30.72(6.37)$ & $31.44(5.03)$ & $30.77(5.13)$ \\
TAFS Total (session 1) & $46.75(14.61)$ & $47.58(15.66)$ & $48.24(15.98)$ \\
TAFS Moral (session 1) & $34.27(12.45)$ & $35.41(12.18)$ & $34.92(11.56)$ \\
TAFS Likelihood (session 1) & $12.48(6.55)$ & $12.17(6.71)$ & $13.35(7.20)$ \\
Positive Mood (session 2) & $5.63(1.17)$ & $5.39(1.31)$ & $5.54(1.11)$ \\
Negative Mood (session 2) & $1.97(1.35)$ & $2.19(1.37)$ & $2.00(1.10)$ \\
\hline
\end{tabular}

Note. $P I O S=$ Penn Inventory of Scrupulosity; IUS =Intolerance of Uncertainty; SCSRFQ=Santa Clara Strength of Religious Faith Questionnaire; TAFS Total = Thought-action Fusion Total;

TAFS Moral=Thought-action Fusion Moral; TAFS Likelihood=Thought-action Fusion

Likelihood 
Table 7

Exploratory Correlations

\begin{tabular}{lllllllllll}
\hline & & Pos & Neg & & & & & & \\
& RG & God & God & SCSRFQ & TAFST & TAFSL & TAFSM & IUS & PIOS & Age \\
\hline RG & 1 & $.24 * *$ & -.07 & $.66^{* *}$ & $.15^{*}$ & .05 & $.17^{*}$ & -.08 & .01 & $.17^{*}$ \\
Pos God & - & 1 & $-.63^{* *}$ & $.27^{* *}$ & .11 & .00 & $.14^{*}$ & -.02 & -.05 & .06 \\
Neg God & - & - & 1 & -.08 & -.02 & .03 & -.04 & -.02 & .07 & -.06 \\
SCSRFQ & - & - & - & 1 & $.33^{* *}$ & .07 & $.38^{* *}$ & .08 & $.19^{* *}$ & .06 \\
TAFST & - & - & - & - & 1 & $.66^{* *}$ & $.91^{* *}$ & .13 & $.31^{* *}$ & -.08 \\
TAFSL & - & - & - & - & - & 1 & $.28^{* *}$ & .07 & $.26^{* *}$ & -.08 \\
TAFSM & - & - & - & - & - & - & 1 & .13 & $.26^{* *}$ & -.06 \\
IUS & - & - & - & - & - & - & - & 1 & $.48^{* *}$ & -.12 \\
PIOS & - & - & - & - & - & - & - & - & -1 & $-.27^{* *}$ \\
Age & - & - & - & - & - & - & - & - & - & 1 \\
\end{tabular}

Note. RG=self-reported relationship with God; Pos God= Positive Concepts of God subscale; Neg God= Negative Concepts of God subscale; SCSRFQ=measure of religiosity; TAFST = Total thought-action fusion; TAFSL =Likelihood thought-action fusion; TAFSM=Moral thought-action fusion; IUS=Intolerance of Uncertainty; PIOS=Penn Inventory of Scrupulosity $* *=$ correlation is significant at the $p<.01$ 
Figure 1

The effect of condition on the mean agreement of the Positive God Concept subscale

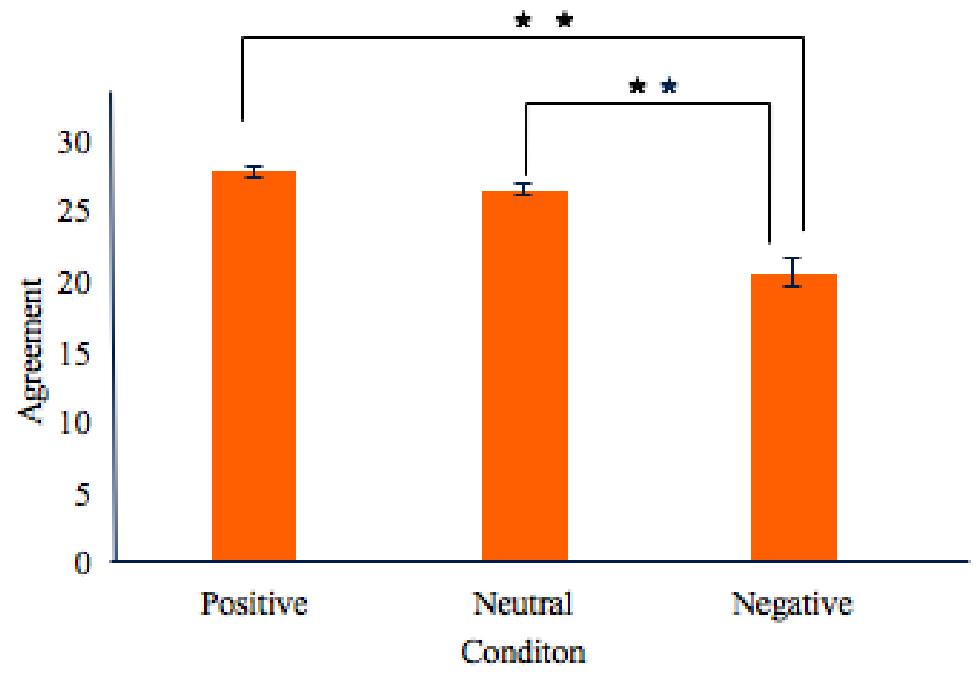

Note. $* * p<.001$ 
Figure 2

The effect of condition on mean agreement of the Negative God Concept subscale

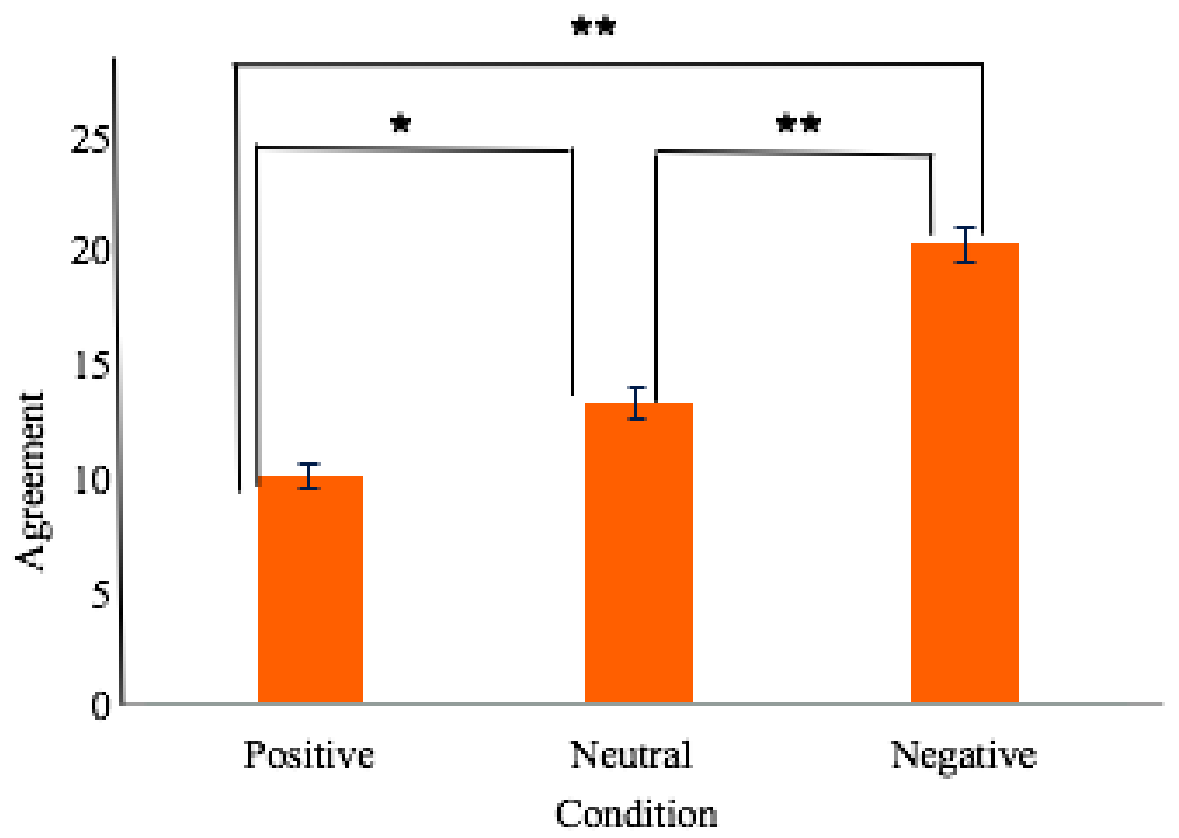

Note. $* * p<.001, * p<.01$ 
Figure 3

The effect of condition on thought-induction task variables

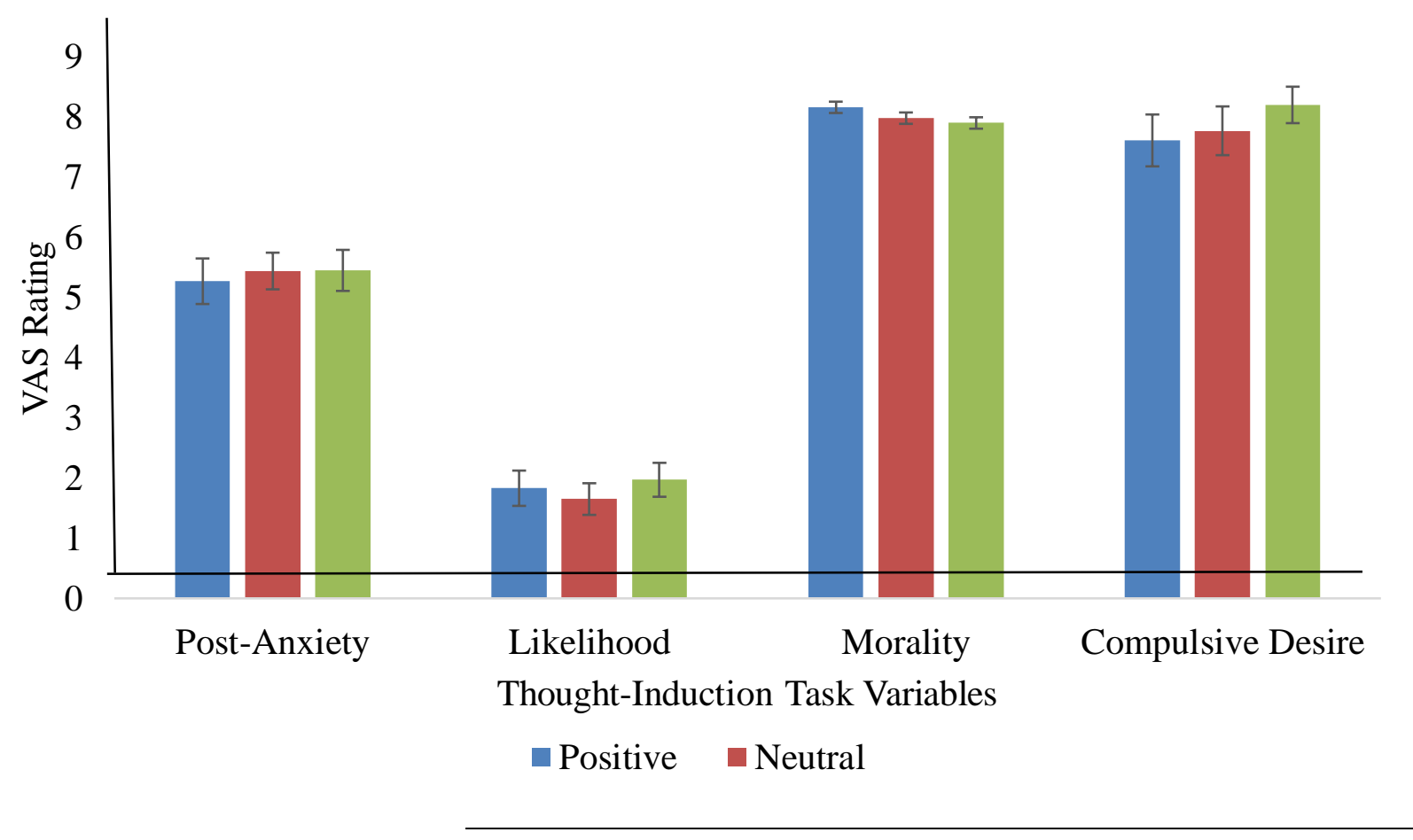

Note. $\mathrm{VAS}=\mathrm{V}$ isual Analogue Scale 


\section{Appendix A: Demographics}

1. Do you self-identify as Christian?
a. Yes
b. No

2. What is your country of residence?
a. The United States
b. Other

3. How old are you in years? (type answer)

4. What is your religious affiliation?
a. Catholic
b. Protestant
c. Eastern Orthodox
d. Oriental Orthodoxy
e. Non-Trinitarian Restoration
f. Other (please describe)

5. How often do you attend religious services?
a. Never
b. Less than once a year
c. About once or twice a year
d. Several times a year
e. About once a month
f. 2-3 times a month
g. Nearly every week
h. Every week
i. Several times a week

6. How often did you attend church as a child?
a. Never
b. Less than once a year
c. About once or twice a year
d. Several times a year
e. About once a month
f. 2-3 times a month
g. Nearly every week
h. Every week
i. Several times a week

7. What is the highest level of education you have completed?
a. Elementary school
b. Middle school
c. High school
d. Some college 
e. College degree (associate's or bachelor's degree)

f. Advanced degree (master's or PhD)

8. What is your ethnicity?

a. Hispanic/Latino

b. Non Hispanic/Latino

c. I prefer not to answer

9. Although the categories listed below may not represent your full identity or use the language you prefer, for the purpose of this survey, please indicate which group below most accurately describes your racial identification (check all that apply).
a. Native American/American Indian/Alaska Native/Indigenous
b. East Asian
c. South Asian
d. Middle Eastern/North African (Non-White)
e. Pacific Islander/Native Hawaiian
f. White
g. Other

10. What is your gender identity?
a. Male
b. Female
c. Transgender
d. Nonbinary/fluid queer/gender queer
e. Other (please describe)

11. Describe your relationship with God.
a. Very good
b. Good
c. Average
d. Bad
e. Very bad 
Appendix B: The Penn Inventory of Scrupulosity

Instructions: The following statements refer to experiences that people sometimes have. Please use the scale below to indicate how much the experience described in each statement is characteristic of you in this moment by writing the appropriate number ( 0 to 4 ) on the line next to each statement.

1=very slightly or not at all; $2=$ a little; $3=$ moderately; 4=quite a bit; 5=extremely

1. I am worrying that I might have dishonest thoughts.

2. I fear I will act immorally.

3. I feel urges to confess sins over and over again.

4. I am worrying about heaven and hell.

5. Feelings of guilt are interfering with my ability to enjoy things I would like to enjoy.

6. Immoral thoughts are in my head and I can't get rid of them.

7. I am afraid my behavior is unacceptable to God.

8. I am trying hard to avoid having certain immoral thoughts.

9. I am very worried that things I did may have been dishonest.

10. I am afraid I will disobey God's rules/laws.

11. I am afraid of having sexual thoughts.

12. I feel guilty about immoral thoughts I have had.

13. I am worrying that God is upset with me.

14. I am afraid of having immoral thoughts.

15. I am afraid my thoughts are unacceptable to God. 
Appendix C: Santa Clara Strength of Religious Faith Questionnaire

Please answer the following questions about religious faith using the scale below. Indicate the level of agreement (or disagreement) for each statement: 1 = strongly disagree; 2 = disagree;

$3=$ agree; 4 = strongly agree

1. My religious faith is extremely important to me.

2. I pray daily.

3. I look to my faith as a source of inspiration.

4. I look to my faith as providing meaning and purpose in my life.

5. I consider myself active in my faith or church.

6. My faith is an important part of who I am as a person.

7. My relationship with God is extremely important to me.

8. I enjoy being around others who share my faith.

9. I look to my faith as a source of comfort.

10. My faith impacts many of my decisions. 


\section{Appendix D: Thought Action Fusion Scale}

Instructions: Please rate your agreement with the following statements using the following scale:

1=strongly disagree, $2=$ disagree, $3=$ neutral, $4=$ agree, $5=$ strongly agree

TAF-Moral

1. Thinking of making an extremely critical remark to a friend is almost as unacceptable to me as actually saying it.

2. Having a blasphemous thought is almost as sinful to me as a blasphemous action.

3. Thinking about swearing at someone else is almost as unacceptable to me as actually swearing.

4. When I have a nasty thought about someone else, it is almost as bad as carrying out a nasty action.

5. Having violent thoughts is almost as unacceptable to me as violent acts.

6. When I think about making an obscene remark or gesture in church, it is almost as sinful as actually doing it.

7. If I wish harm on someone, it is almost as bad as doing harm.

8. If I think about making an obscene gesture to someone else, it is almost as bad as doing it.

9. When I think unkindly about a friend, it is almost as disloyal as doing an unkind act.

10. If I have a jealous thought, it is almost the same as making a jealous remark.

11. Thinking of cheating in a personal relationship is almost as immoral to me as actually cheating.

12. Having obscene thoughts in a church is unacceptable to me.

TAF-Likelihood-Others

1. If I think of a relative/friend losing their job, this increases the risk that they will lose their job.

2. If I think of a relative/friend being in a car accident, this increases the risk that he/she will have a car accident.

3. If I think of a friend/relative being injured in a fall, this increases the risk that he/she will have a fall and be injured.

4. If I think of a relative/friend falling ill this increases the risk that he/she will fall ill.

TAF-Likelihood-Self

1. If I think of myself being injured in a fall, this increases the risk that I will have a fall and be injured.

2. If I think of myself being in a car accident, this increases the risk that I will have a car accident.

3. If I think of myself falling ill, this increases the risk that I will fall ill. 
Appendix E: Intolerance of Uncertainty Scale-Short Form

Please circle the number that best corresponds to how much you agree with each statement.

Not at all A little Somewhat Very Entirely characteristic characteristi characteristic characterist characteristi of me c of me of me ic of me c of me

1. Unforeseen events upset me greatly.

1

2. It frustrates me not having all the 1 information I need.

3. Uncertainty keeps me from living a full life.

4. One should always look ahead so as to avoid surprises.

5. A small unforeseen event can spoil everything, even with the best of planning.

6. When it's time to act, uncertainty paralyses me.

7. When I am uncertain I can't function very well.

8. I always want to know what the future has in store for me.

9. I can't stand being taken by surprise.

10. The smallest doubt can stop me from acting.

11. I should be able to organize everything in advance.

12. I must get away from all uncertain situations.

$\begin{array}{llll}2 & 3 & 4 & 5\end{array}$

23

4

4

4

4

4

4

4

4

4

4

4

5 


\section{Negative Six Verse Condition}

\section{Appendix F: God Concept Primes}

Deuteronomy 31:17

17 Then my anger will blaze forth against them. I will abandon them, hiding my face from them, and they will be devoured. Terrible trouble will come down on them, and on that day they will say, 'These disasters have come down on us because God is no longer among us!'

Luke 12:5

5 But I'll tell you whom to fear. Fear God, who has the power to kill you and then throw you into hell. Yes, he's the one to fear.

Psalm 68:21

21 But God will smash the heads of his enemies, crushing the skulls of those who love their guilty ways.

Ezekiel 25:17

17 I will execute terrible vengeance against them to punish them for what they have done. And when I have inflicted my revenge, they will know that I am the Lord."

Leviticus 26:27-29

27 "If in spite of all this you still refuse to listen and still remain hostile toward me, 28 then I will give full vent to my hostility. I myself will punish you seven times over for your sins. 29 Then you will eat the flesh of your own sons and daughters.

Isaiah 13:9

9 For see, the day of the Lord is comingthe terrible day of his fury and fierce anger.

The land will be made desolate, and all the sinners destroyed with it.

\section{Positive Six Verse Condition}

Romans 8:38-39

38 And I am convinced that nothing can ever separate us from God's love. Neither death nor life, neither angels nor demons, neither our fears for today nor our worries about tomorrow-not even the powers of hell can separate us from God's love. 39 No power in the sky above or in the earth below-indeed, nothing in all creation will ever be able to separate us from the love of God that is revealed in Christ Jesus our Lord.

Zephaniah 3:17

17 For the Lord your God is living among you.

He is a mighty savior.

He will take delight in you with gladness. 
With his love, he will calm all your fears.

He will rejoice over you with joyful songs."

Jeremiah 29:11

11 For I know the plans I have for you," says the Lord. "They are plans for good and not for disaster, to give you a future and a hope.

Isaiah 41:13

13 For I hold you by your right hand-

I, the Lord your God.

And I say to you,

'Don't be afraid. I am here to help you.

Psalm 121:5-8

5 The Lord himself watches over you!

The Lord stands beside you as your protective shade.

6 The sun will not harm you by day, nor the moon at night.

7 The Lord keeps you from all harm and watches over your life.

8 The Lord keeps watch over you as you come and go, both now and forever.

Psalm 103:2-5

2 Let all that I am praise the Lord; may I never forget the good things he does for me.

3 He forgives all my sins and heals all my diseases.

4 He redeems me from death and crowns me with love and tender mercies.

5 He fills my life with good things.

My youth is renewed like the eagle's!

\section{Neutral Six Verse Condition}

Proverbs 22:2

2 The rich and poor have this in common:

The Lord made them both.

Judges 13:8-10

8 Then Manoah prayed to the Lord, saying, "Lord, please let the man of God come back to us again and give us more instructions about this son who is to be born." 
9 God answered Manoah's prayer, and the angel of God appeared once again to his wife as she was sitting in the field. But her husband, Manoah, was not with her. 10 So she quickly ran and told her husband, "The man who appeared to me the other day is here again!"

Deuteronomy 4:35

35 "He showed you these things so you would know that the Lord is God and there is no other.

Genesis 35:6-7

6 Eventually, Jacob and his household arrived at Luz (also called Bethel) in Canaan. 7 Jacob built an altar there and named the place El-bethel (which means "God of Bethel"), because God had appeared to him there when he was fleeing from his brother, Esau.

1 Corinthians 2:10-11

10 But it was to us that God revealed these things by his Spirit. For his Spirit searches out everything and shows us God's deep secrets. 11 No one can know a person's thoughts except that person's own spirit, and no one can know God's thoughts except God's own Spirit.

Isaiah 55:8-9

8 "My thoughts are nothing like your thoughts," says the Lord.

"And my ways are far beyond anything you could imagine.

9 For just as the heavens are higher than the earth, so my ways are higher than your ways and my thoughts higher than your thoughts. 


\section{Appendix G: God Concept Checklist}

Instructions: Please rate your agreement with how well the following adjectives describe God using the following key: 1= strongly disagree, $2=$ disagree, $3=$ neither disagree or agree, $4=$ agree, $5=$ strongly agree

1. Peaceful

2. Vengeful

3. Fearsome

4. Kind

5. Comforting

6. Terrifying

7. Jealous

8. Gentle

9. Angry

10. Compassionate

11. Loving

12. Punishing 